\title{
Human galectin-3 (Mac-2 antigen): Defining molecular switches of affinity to natural glycoproteins, structural and dynamic aspects of glycan binding by flexible ligand docking and putative regulatory sequences in the proximal promoter region
}

\author{
Mickaël Krzeminski ${ }^{\mathrm{a}, 1}$, Tanuja Singh ${ }^{\mathrm{b}, \mathrm{c}, 1}$, Sabine André ${ }^{\mathrm{b}}$, Martin Lensch ${ }^{\mathrm{b}}$, Albert M. Wu ${ }^{\mathrm{c}, *}$, \\ Alexandre M.J.J. Bonvin ${ }^{\mathrm{a}, *}$, Hans-Joachim Gabius ${ }^{\mathrm{b}, *}$ \\ a Bijvoet Center for Biomolecular Research, Faculty of Science, Utrecht University, Padualaan 8, 3584 CH Utrecht, The Netherlands \\ ${ }^{\mathrm{b}}$ Institute of Physiological Chemistry, Faculty of Veterinary Medicine, Ludwig-Maximilians-University, Veterinärstr. 13, 80539 Munich, Germany \\ c Glyco-Immunochemistry Research Laboratory, Institute of Molecular and Cellular Biology, College of Medicine, Chang-Gung University, Kwei-san, Tao-yuan 333, Taiwan
}

\section{A R T I C L E I N F O}

\section{Article history:}

Received 27 August 2010

Received in revised form 29 October 2010

Accepted 2 November 2010

Available online 8 November 2010

\section{Keywords:}

Glycosylation

Lectin

Macrophage

Modeling

Mucin

Sialylation

\begin{abstract}
A B S T R A C T
Background: Human galectin-3 (Mac-2 antigen) is a cell-type-specific multifunctional effector owing to selective binding of distinct cell-surface glycoconjugates harboring $\beta$-galactosides. The structural basis underlying the apparent preferences for distinct glycoproteins and for expression is so far unknown. Methods: We strategically combined solid-phase assays on 43 natural glycoproteins with a new statistical approach to fully flexible computational docking and also processed the proximal promoter region in silico. Results: The degree of branching in $\mathrm{N}$-glycans and clustering of core $1 \mathrm{O}$-glycans are positive modulators for avidity. Sialylation of $\mathrm{N}$-glycans in $\alpha 2-6$ linkage and of core 10 -glycans in $\alpha 2-3$ linkage along with core 2 branching was an unfavorable factor, despite the presence of suited glycans in the vicinity. The lectin-ligand contact profile was scrutinized for six natural di- and tetrasaccharides enabling a statistical grading by analyzing flexible docking trajectories. The computational analysis of the proximal promoter region delineated putative sites for Lmo2/c-Ets-1 binding and new sites with potential for RUNX binding. General significance: These results identify new features of glycan selectivity and ligand contact by combining solid-phase assays with in silico work as well as of reactivity potential of the promoter.
\end{abstract}

(c) 2010 Elsevier B.V. All rights reserved.

\section{Introduction}

Protein-glycan recognition is being delineated as a key molecular interaction route based on the exceptional capacity of oligosaccharides for high-density information coding and the emergence of various families of lectins [1]. Despite the glycomic diversity on cell surfaces this process has an exquisite target selectivity which underlies the precision of the post-binding biosignaling [2]. To

Abbreviations: BSM, bovine submaxillary mucin; Gal, D-galactose; GalNAc, $N$-acetylD-galactosamine; Glc, D-glucose; GlcNAc, N-acetyl-D-glucosamine; gp, glycoprotein; HADDOCK, High Ambiguity Driven DOCKing; hGal-3, human galectin-3; LacNAc, $\mathrm{N}$ acetyllactosamine; LacdiNAc, di-N-acetylated lactose; Man, D-mannose; OSM, ovine submaxillary mucin; PSM, porcine submaxillary mucin; THGP, Tamm-Horsfall urinary glycoprotein; TBS-T, Tris/HCl-buffered saline containing 0.05\% Tween 20; TF, ThomsenFriedenreich antigen (Gal $\beta 1-3$ GalNAc $\alpha$ )

* Corresponding authors. A.M. Wu is to be contacted at tel.: + 8863211 8966; fax: +8863211 8456, + 88632118700 . A.M.J.J. Bonvin, tel.: + 31302533850 ; fax: + 3130 2537623. H.-J. Gabius, tel.: +49892180 2290; fax: + 498921802508 .

E-mail addresses: amwu@mail.cgu.edu.tw (A.M. Wu), a.m.j.j.bonvin@uu.n

(A.M.J.J. Bonvin), gabius@lectins.de (H.-J. Gabius).

1 These authors contributed equally to this manuscript. define the nature of the mechanisms and the structural basis for the inherent selectivity are thus questions with conspicuous biorelevance. Here, we present a combined approach toward this end, studying binding preferences of a multifunctional human lectin. We tested various ligand structures and topology of presentation in combination with flexible ligand docking and statistical analysis of contact.

The Mac-2 antigen was originally defined as rat macrophage marker present abundantly on thioglycollate-induced peritoneal exudate cells [3]. It was later confirmed to be expressed in the monocyte-macrophage lineage and detected also in epithelial and stromal cells as well as in diverse tumor cell types [4-6]. The human Mac-2 protein, known as major non-integrin binding partner for laminin and IgE receptor, was then identified to be a $\beta$-galactosidespecific lectin [7]. The characteristics of the C-terminal sequence section, the lectin part, led to its assignment to the galectin family, herein as galectin-3 [8,9]. Its lectin property plays an important role in defense mechanisms. For instance, it enables macrophages to target di- $N$-acetylated lactose (LacdiNAc) of helminth parasites and the major xenoantigen ( $\alpha$-Gal) [10,11]. Evidently, distinct glycan epitopes serve as sugar-encoded signals for the lectin in immune defense. This 
also holds true for adhesion/growth-regulatory events triggered by galectin-3, observed for example with thymocytes or carcinoma/ neuroblastoma cells $[2,12-15]$.

To exert its specific functions, human galectin-3 (hGal-3) requires a discriminatory reactivity to the different types of oligosaccharides based on a substituted $\beta$-galactoside core in natural glycoconjugates. Binding and inhibition assays, frontal affinity chromatography, glycan arrays and titration calorimetry revealed a strong reactivity with $\beta 1-$ 4-linked galactosides, especially oligomeric $\mathrm{N}$-acetyllactosamine (LacNAc), and histo-blood group $\mathrm{ABH}$ epitopes with indications for a minor influence of $\alpha 2-3$-sialylation and $\mathrm{N}$-glycan branching in free glycans, and assay-dependent variation of avidity for $\mathrm{N}$ - vs $\mathrm{O}$-glycans [16-25]. Due to the rather common presence of theoretically suited epitopes at the termini of glycan branches, binding of hGal-3 to many cell surface glycoconjugates can be expected. But, however, this lectin is very selective when engaging in contacts with cell surface glycoconjugates.

Despite the abundance of glycoconjugates with terminal $\beta$ galactosides only a limited set of glycoproteins/glycolipids qualifies as physiological galectin-3 ligand, and this with cell-type selectivity. Testing for example colon cancer cells, carcinoembryonic antigen, laminin and lysosome-associated membrane proteins $1 / 2$ as well as mucins (especially the mucin MUC1 via $\mathrm{O}$-glycans and the $\mathrm{N}$-glycan of MUC1-C at Asn36) were bioactive [15,26-28]. The glycoproteins CD29, CD43, CD45, CD71, and CD98 (H-chain) and the Mac-2-binding protein were counterreceptors in the case of thymocytes, for hippocampal neurons the neural cell adhesion molecule L1 and for neuroblastoma cells ganglioside GM1 $[13,14,29]$. Thus, the presence of a cognate carbohydrate structure combined with other, not yet precisely defined topological factors appears to underlie the distinct binding properties. It is noteworthy in this context that hGal-3's tridomain structure, especially its five collagenase-sensitive tandem-repeat modules, endows the only chimera-type member of this lectin family with unique properties for cooperativity of binding and oligomerization in the presence of multivalent ligands [30-33]. This characteristic gives special reason to test natural glycoproteins with different degrees of valency and branch-end structure. Compared to free $\mathrm{N}$ - and $\mathrm{O}$-glycans the spatial distribution of the glycan chains attached to a protein carrier is assumed to partake in regulation of lectin affinity [34-36]. To what extent factors imposed by glycan presentation on a natural protein affect the binding of this potent effector in the immune system and beyond has not yet been addressed. In order to take the fine-specificity analysis of hGal-3 to the topological level, probing well-characterized glycoproteins comparatively under identical conditions is a promising approach.

We analyze here 43 glycoprotein preparations with differences in branch-end and core structures including sialylation and in degree of branching as well as a bacterial polysaccharide. These binding assays are supplemented with fine-specificity monitoring using 41 glycan compounds as inhibitors of hGal-3/glycoprotein binding. The experimental part is combined with in silico calculations to monitor the range of interactions in complexes with six cognate di- and tetrasaccharides. Using HADDOCK version 2.1 [37,38], a flexible docking approach that has been introduced previously to the study of protein-carbohydrate interactions [39], we visualize the dynamics within the interaction profile of a lectin for the first time at a statistical level. The presented results contribute to the efforts to explain the origin of affinity, specificity and eventually intrafamily differences in physiological ligand selection, with implications for drug design. These differences are also manifested on the level of the expression patterns of galectins, for example detected by immunohistochemical fingerprinting of human tumors with prognostic relevance [40-42]. To help delineate the underlying sequence signals, we present a comparative in silico dissection of the proximal promoter region of the hGal-3 gene with those of three proto-type galectins, a step to spot putative sites for transcription factors and discern non-uniform features.

\section{Materials and methods}

\subsection{Galectin-3}

Human galectin-3 was obtained by recombinant production and purified by affinity chromatography on lactosylated Sepharose 4B, prepared after resin activation with divinyl sulfone, as crucial step. It was subjected to rigorous quality controls by one- and twodimensional gel electrophoresis, gel filtration and mass spectrometry, then biotinylated under activity-preserving conditions with the $\mathrm{N}$ hydroxysuccinimide ester derivative of biotin [12,31]. The degree of biotinylation was determined by two-dimensional gel electrophoresis and mass spectrometric fingerprinting $[43,44]$. Lack of influence of the labeling on lectin activity was ascertained by solid-phase and cellbinding assays using asialofetuin and human SW480 colon carcinoma cells, respectively $[45,46]$.

\subsection{Glycoproteins and saccharides}

Sources and further processing of the glycoproteins have been given previously in the first reports on galectin reactivity $[47,48]$. The predominant carbohydrate determinants at branch ends with affinity to galectins are listed in Table 1. Due to its importance for galectin binding, information on branch-end sialylation is as follows for the tested glycoproteins:

- $\mathrm{N}$-glycans of bovine lactoferrin are exclusively $\alpha 2-6$-sialylated, and in addition terminal LacdiNAc and Gal $\alpha 1-3$ Galß1-4GlcNAc (B-like) epitopes are present [49]. The same applies to human glycophorin, which can naturally present terminal galactose in one arm due to incomplete sialylation [50].

- Porcine thyroglobulin, human $\alpha_{1}$-acid glycoprotein and bovine fetuin all contain $\alpha 2-3 / 6$-sialylated $N$-acetyllactosamine with branch specificity, e.g. $\alpha 2-3$ sialylation resides in the $\beta 1-4$-branch of the $\alpha 1-3$-arm (for further information, please see [51]).

The Pneumococcus type 14 polysaccharide was a generous gift from the late Dr. E. A. Kabat (Department of Microbiology, Columbia University, NY, USA). Mono-, di- and oligosaccharides used were obtained from Dextra (Reading, Berkshire, UK) or Sigma (Munich, Germany).

\subsection{Enzyme-linked lectinosorbent assay}

The assay was performed under conditions deliberately kept constant to allow comparison of the different galectins tested $[39,47,48,52]$. In detail, the volume of each reagent solution applied to wells of the plate was $50 \mu \mathrm{l} /$ well, and all incubations, except for coating, were performed at $20^{\circ} \mathrm{C}$. The reagents, if not indicated otherwise, were diluted with Tris-buffered saline (TBS; 0.05 M Tris$\mathrm{HCl}, 0.15 \mathrm{M} \mathrm{NaCl}, \mathrm{pH} 7.35$ ) containing $0.05 \%$ Tween 20 (TBS-T). TBS-T was used for washing the plates between incubation steps.

The surface of the 96-well microtiter plate wells (Nunc-Immuno, Kamstrupvej, Denmark) was coated with glycoproteins dissolved in $0.05 \mathrm{M}$ sodium carbonate buffer $\left(0.05 \mathrm{M} \mathrm{NaHCO}_{3} / 0.05 \mathrm{M} \mathrm{Na}_{2} \mathrm{CO}_{3}, \mathrm{pH}\right.$ 9.6) overnight at $4{ }^{\circ} \mathrm{C}$. After washing the plate, solution with biotinylated hGal-3 ( $5 \mu \mathrm{g} / \mathrm{ml})$ was added and the plate was incubated for $30 \mathrm{~min}$. The plates were then carefully washed to remove any free lectin. The ExtrAvidin/alkaline phosphatase solution (diluted $1: 10,000$; Sigma) was added thereafter to detect the specifically bound hGal-3 by its biotin moieties. Carbohydrate dependence of binding was routinely ascertained by haptenic inhibition. After $1 \mathrm{~h}$ the plates were washed at least four times to remove free conjugate and incubated with a solution of p-nitrophenyl phosphate (Sigma 
Table 1

Reactivity of hGal-3 for natural glycoproteins (gps).

\begin{tabular}{|c|c|c|c|}
\hline \multirow[t]{2}{*}{ Glycoprotein (terminal epitope) ${ }^{\mathrm{b}}$} & \multirow{2}{*}{$\begin{array}{l}1.5\left(\mathrm{~A}_{405}\right) \\
\text { unit (ng) }\end{array}$} & \multicolumn{2}{|c|}{ Maximum $\mathrm{A}_{405}$ absorbance } \\
\hline & & Absorbance reading ${ }^{\mathrm{c}}$ & Binding intensity ${ }^{\mathrm{c}}$ \\
\hline \multicolumn{4}{|l|}{ Histo-blood group precursor (equivalent) gps } \\
\hline Cyst Tij $20 \%$ of second $10 \%\left(\mathbf{B}_{\mathrm{h}}>\mathbf{I} / \mathbf{I I}\right)$ & 8.0 & 4.2 & ++++ \\
\hline Cyst Beach P-1 (I/II) & 70.0 & 2.9 & +++++ \\
\hline Cyst OG $10 \% 2 x$ ppt (I/II) & 80.0 & 3.6 & +++++ \\
\hline Cyst MSS 1st Smith degraded (I/II) & 200.0 & 1.8 & +++ \\
\hline Cyst Mcdon P-1 (I/II) & - & 1.0 & ++ \\
\hline Cyst Tighe P-1 (I/II) & - & 0.6 & + \\
\hline Hog gastric mucin \#14 (A, II on core 2 and I-active 0 -glycans) & - & 0.3 & \pm \\
\hline Hog gastric mucin \#21 (II on core 2 and I-active 0 -glycans) & - & 0.2 & \pm \\
\hline \multicolumn{4}{|l|}{ Histo-blood group ABH-active gps } \\
\hline Cyst $19\left(\mathbf{B}_{\mathrm{h}}>\mathbf{L} \mathbf{e}^{\mathbf{b}}, \mathbf{L e}^{\mathbf{y}}\right)$ & 32.0 & 4.1 & +++++ \\
\hline Cyst Beach phenol insoluble $\left(\mathbf{B}_{\mathrm{h}}>\mathbf{L} \mathbf{e}^{\mathbf{b}}, \mathbf{L e}^{\mathbf{y}}\right)$ & 120.0 & 2.9 & +++++ \\
\hline Cyst MSM $10 \%$ ppt $\left(\mathbf{A}_{\mathbf{h}}\left[\mathbf{A}_{2}\right]>\mathbf{L e}^{\mathbf{b}}, \mathbf{L e}^{\mathbf{y}}\right)$ & - & 1.3 & ++ \\
\hline Hog gastric mucin \#9 ( $\mathbf{A}_{\mathbf{h}}, \mathbf{H}$ on core 2 and I-active 0 -glycans) & - & 1.1 & ++ \\
\hline Cyst MSS $10 \% 2 x\left(\mathbf{A}_{\mathbf{h}}>\mathbf{L} \mathbf{e}^{\mathbf{b}}, \mathbf{L e}^{\mathbf{y}}\right)$ & - & 1.0 & ++ \\
\hline Cyst Mcdon $\left(\mathbf{A}_{\mathbf{h}}>\mathbf{L} \mathbf{e}^{\mathbf{b}}, \mathbf{L e}^{\mathbf{y}}\right)$ & - & 0.7 & + \\
\hline Hog gastric mucin \#4 ( $\mathbf{A}_{\mathbf{h}}, \mathbf{H}$ on core 2 and I-active $O$-glycans) & - & 0.5 & + \\
\hline \multicolumn{4}{|l|}{ Lewis $^{a}$ - and Lewis ${ }^{b}$-active gps } \\
\hline Cyst N-1 Le ${ }^{\mathrm{a}} 20 \%$ 2x $\left(\mathbf{L e}^{\mathbf{a}}, \mathbf{L e}^{\mathbf{x}}\right)$ & - & 0.9 & + \\
\hline Asialo HOC $350\left(\mathbf{L e}^{\mathrm{a}}\right)$ & - & 0.6 & + \\
\hline Cyst Tighe phenol insoluble $\left(\mathbf{H}, \mathbf{L e}^{\mathbf{a}}, \mathbf{L e}^{\mathbf{b}}, \mathbf{L e}^{\mathbf{x}}, \mathbf{L e}^{\mathbf{y}}\right)$ & - & 0.2 & \pm \\
\hline HOC 350 (sialyl Le Le $^{\mathrm{a}}$ ) & - & 0.1 & - \\
\hline \multicolumn{4}{|l|}{ Multi-antennary Galß1-4GlcNAc (II) gps } \\
\hline Human asialo $\alpha_{1}$-acid gp (mII) & 25.0 & 2.9 & +++++ \\
\hline Bovine asialolactoferrin (mII, B, LacdiNAc) & 35.0 & 4.2 & +++++ \\
\hline THGP Sd $\left(\mathrm{a}^{+}\right)$W. M. (S, iII $)$ & 40.0 & 3.3 & +++++ \\
\hline Asialo THGP Sd $\left(\mathrm{a}^{+}\right)$W. M. (S, iII) & 55.0 & 2.9 & +++++ \\
\hline Bird nest asialo gp (E, iII, $\left.\mathbf{T}_{\boldsymbol{\alpha}}\right)$ & 60.0 & 3.9 & +++++ \\
\hline Porcine thyroglobulin ( $\alpha 2-3 / 6$ sialyl $\mathbf{m I I})$ & 60.0 & 1.9 & +++ \\
\hline Porcine asialothyroglobulin (mII) & 80.0 & 1.8 & +++ \\
\hline Human asialolactoferrin (mII, iII, $\mathbf{L e}^{\mathbf{x}}$ ) & 500.0 & 1.7 & +++ \\
\hline Asialofetuin (mII/I, $\left.\mathbf{T}_{\boldsymbol{\alpha}}\right)$ & - & 1.0 & ++ \\
\hline Bovine lactoferrin ( $\alpha 2-6$ sialyl mII, B, LacdiNAc) & - & 0.9 & + \\
\hline Bovine asialo $\alpha_{1}$-acid gp (mII) & - & 0.8 & + \\
\hline Bird nest gp (E, iII, sialyl $\left.\mathbf{T}_{\boldsymbol{\alpha}}\right)$ & - & 0.4 & \pm \\
\hline Human $\alpha_{1}$-acid gp ( $\alpha 2-3 / 6$ sialyl mII $)$ & - & 0.4 & \pm \\
\hline Pneumococcus type 14 polysaccharide (iII/Lac) & - & 0.3 & \pm \\
\hline Bovine $\alpha_{1}$-acid gp (sialyl mII) & - & 0.1 & - \\
\hline Fetuin $\left(\alpha 2-3 / 6\right.$ sialyl mII/I, sialyl/disialyl $\left.\mathbf{T}_{\boldsymbol{\alpha}}\right)$ & - & 0.0 & - \\
\hline \multicolumn{4}{|l|}{$\boldsymbol{T}$, Tn-containing gps } \\
\hline Human asialoagalactoglycophorin $\left(\mathbf{T}_{\boldsymbol{\alpha}}, \mathrm{Tn}\right)$ & 400.0 & 1.6 & +++ \\
\hline Human asialoglycophorin $\left(\mathbf{T}_{\boldsymbol{\alpha}}, \mathrm{Tn}, \mathrm{mIIb} / \mathbf{f}\right)$ & - & 1.4 & ++ \\
\hline Human glycophorin ( sialyl $\mathbf{T}_{\boldsymbol{\alpha}}, \mathrm{Tn}, \alpha 2-6$ sialyl mIIlb/f) & - & 0.5 & + \\
\hline OSM (sialyl Tn, $\mathbf{T}_{\boldsymbol{\alpha}}$, core 2 II) & - & 0.0 & - \\
\hline Asialo OSM (Tn, $\mathbf{T}_{\boldsymbol{\alpha}}$, core 2 II) & - & 0.0 & - \\
\hline PSM (sialyl Tn, $\mathbf{T}_{\boldsymbol{\alpha}}, \mathbf{A}, \mathbf{A}_{\mathrm{h}}, \mathbf{H}$ ) & - & 0.1 & - \\
\hline Asialo PSM (Tn, $\left.\mathbf{T}_{\boldsymbol{\alpha}}, \mathbf{A}, \mathbf{A}_{\mathrm{h}}, \mathbf{H}\right)$ & - & 0.1 & - \\
\hline BSM ( sialyl Tn, GlcNAc $\beta 1-3 \mathbf{T n}, \mathbf{T}_{\boldsymbol{\alpha}}$ ) & - & 0.0 & - \\
\hline Asialo BSM (Tn, GlcNAcß1-3Tn, $\mathbf{T}_{\boldsymbol{\alpha}}$ ) & - & 0.0 & - \\
\hline
\end{tabular}

a Analyses were carried out by ELLSA. $250 \mathrm{ng}$ of biotinylated hGal-3 was applied in solid-phase assays using various gps, ranging from $0.4 \mu \mathrm{g}$ to $5 \mu \mathrm{g}$.

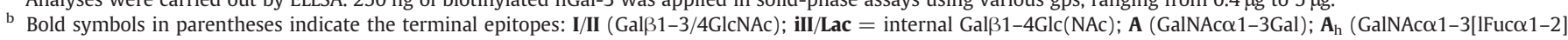

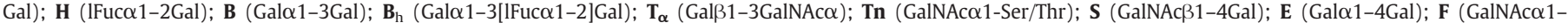
3GalNAc); $\mathrm{m}=$ multi-antennary; $\mathrm{mIIb} / \mathbf{f}=$ bi-antennary $\mathrm{N}$-glycan with core fucosylation and bisecting GlcNAc.

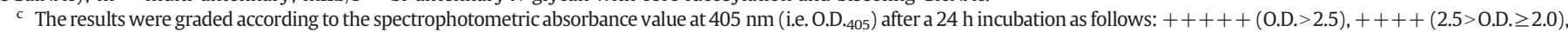
$+++(2.0>0$. D. $\geq 1.5),++(1.5>0$. D. $\geq 1.0),+(1.0>0$. D. $\geq 0.5), \pm(0.5>0$. D. $\geq 0.2)$, and $-(0$. D. $<0.2)$.

phosphatase substrate $5 \mathrm{mg}$ tablets) in $0.05 \mathrm{M}$ carbonate buffer, $\mathrm{pH}$ 9.6, containing $1 \mathrm{mM} \mathrm{MgCl} 2$ (1 tablet/5 $\mathrm{ml}$ ). The resulting absorbance was read at $405 \mathrm{~nm}$ in a microtiter plate reader after an incubation of $24 \mathrm{~h}$ at $20^{\circ} \mathrm{C}$ in the dark with the substrate-containing solution. For inhibition studies, serially diluted inhibitor samples were mixed with an equal volume of hGal-3-containing solution. The inhibitory activity was determined from the inhibition curve and expressed as the amount of inhibitor (ng or nmol per well) giving $50 \%$ inhibition of the control binding.

\subsection{Computational interaction analysis}

Conformational analysis of free-state ligands was performed by molecular mechanics calculations yielding $\Phi, \Psi$, E-plots for each glycoside linkage, as described previously [53,54]. The interaction with di- and oligosaccharides was modeled starting from the crystal structure of hGal-3 at $1.40 \AA$ A-resolution [55; PDB code $1 \mathrm{KJL}$ ] using the information-driven flexible docking program HADDOCK version 2.1 $[37,38]$ as described previously [39]. Restraints used to drive the 
docking are a set of four key hydrogen bonds defined as follows: $\mathrm{O}^{4}$ oxygen atom with $\mathrm{N}_{\varepsilon^{2}}$ of His158 and $\mathrm{N}_{\eta}{ }^{*}$ of $\operatorname{Arg} 162$, the $0^{5}$ oxygen atom with $\mathrm{N}_{\eta}{ }^{*}$ of $\operatorname{Arg} 162$, and the $\mathrm{O}^{6}$ oxygen atom with $\mathrm{N}_{\delta^{2}}$ of Asn 174 . This selection was guided by typical loss of affinity for methyl $\beta$ lactoside in galectins upon loss of one of the hydroxyl groups at the C4/C6-positions of galactose [56]. Protein-ligand docking included full flexibility of the carbohydrate during the simulated annealing stage while the lectin flexibility was increased stepwisely, starting with the side chains and then including the backbone [39]. The resulting models were subjected to a final refinement in explicit solvent (water) and clustered based on their pairwise RMSD values. The energetic contribution of each lectin residue to the binding was further analyzed. Finally, a statistical contact analysis was newly added to the procedure. Irrespective of their energy ranking, 1000 complexes with GalB1-4GlcNAc ( $N$-acetyllactosamine; LacNAc-II) the test case to be compared with the crystal structure - 1500, complexes with the disaccharides LacdiNAc, LacNAc-I and Galß13GalNAc as well as 500 complexes with the histo-blood group A- and B-tetrasaccharides, respectively, were monitored. The motion pictures visualizing the docking process were generated with PyMol (http:// pymol.org), also using VideoMach (http://gromada.com/videomach/ videomach.php) to set up the movie.

\subsection{Bioinformatic promoter analysis}

The proximal promoter regions (from -2000 bp upstream of the transcription start to +200 bp downstream) of the genes for hGal-3 and the homodimeric proto-type galectins- $1,-2$ and -7 were subjected to processing by the Match ${ }^{\mathrm{TM}} / \mathrm{P}-\mathrm{Match}^{\mathrm{TM}}$ programs with presettings designed to minimize number of positive hits, while avoiding to exclude a considerable number of sites for common factors with low-quality weight matrices $[57,58]$.

\section{Results}

\subsection{Glycoproteins as ligands}

The reactivity profile of hGal-3 with natural glycoproteins was determined in a solid-phase assay. Labeled lectin with up to seven biotin groups attached to lysine residues was used as probe in solution to determine the extent of binding to the surface-immobilized glycoproteins. To maintain constant conditions for signal development aliquots of the same batch of biotinylated lectin were tested. Controls with asialofetuin ascertained the carbohydrate-dependent binding activity as well as the dependence on lectin concentration and coating density. Further controls with serum albumin and the highmannose-type glycoprotein ovalbumin excluded binding via proteinprotein interactions or the $\mathrm{N}$-glycan core. Due to hGal-3's basic isoelectric point ( $\mathrm{pI}$ 8.58) the possibility of binding by ionic interactions with the sialic acid, especially to mucin-type 0 -glycans, has to be considered. As shown in Table 1, sialylation did not automatically lead to reactivity, and, if detectable, blocking by lactose but not sucrose revealed dependence of binding on $\beta$-galactoside. The essential nature of galactose for binding was demonstrated by a complete loss of reactivity of asialofetuin upon enzymatic degalactosylation.

With the lectin concentration set in the linear range at $5 \mu \mathrm{g} / \mathrm{ml}$, binding curves were measured for each glycoprotein (for an example see Fig. 1). To allow comparison with previous reports, the binding data were normalized to the amount of glycoproteins (in ng for coating) required to reach an absorbance of $1.5 \mathrm{OD}$ at $405 \mathrm{~nm}$. At $4 \mathrm{~h}$ incubation, only few glycoproteins surpassed this limit, i.e. bovine asialolactoferrin with its $\mathrm{N}$-glycans and fractions of human ovarian cystic fluid with GalB1-3/4GlcNAc (I, II) and B termini. The number of active glycoproteins increased by extending this period to $24 \mathrm{~h}$ (Table 1).

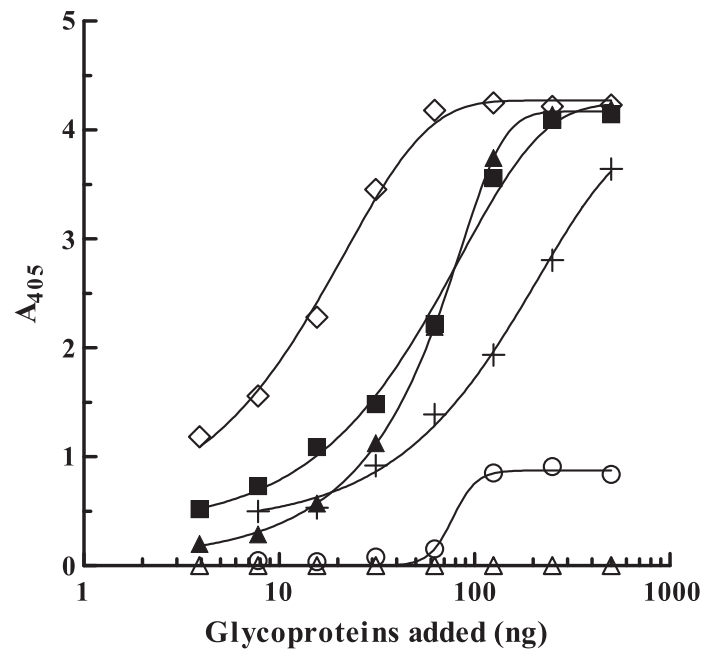

Fig. 1. Binding of hGal-3 to microtiter plates coated with six different glycoproteins at decreasing density. Biotinylated hGal-3 $(5 \mu \mathrm{g} / \mathrm{ml})$ was used to determine extent of binding comparatively to the glycoproteins: cyst Tij $20 \%$ of second $10 \%(\diamond)$, cyst $19(\boldsymbol{\square})$, bovine asialolactoferrin $(\mathbf{\Lambda})$, bird nest asialo gp $(+)$, bovine lactoferrin $(O)$ and asialo $\operatorname{OSM}(\triangle)$. The standard deviation did not exceed $10 \%$. Total volume of the assay was $50 \mu \mathrm{l} . \mathrm{A}_{405}$ was recorded after a $24 \mathrm{~h}$ incubation.

Human galectin-3 reacts both with $\mathrm{O}$ - and $\mathrm{N}$-glycans presented in the natural context. A clear preference for core 1 structures, e.g. present in glycophorin, relative to core 20 -glycans (even with I reactivity) in hog gastric mucin was detected (Table 1 ). Terminal presence of histo-blood group $\mathrm{ABH}$ epitopes can in part compensate the low reactivity of the core 2 structure. However, a given density threshold must be surpassed, as revealed in the case of porcine submaxillary mucin (PSM) (Table 1). Equally noteworthy, the presentation of $T_{n}$ together with $T_{\alpha}$ in ovine salivary glycoprotein (OSM) was not sufficient to generate binding, whereas the 15 clustered 0 -glycans with $\mathrm{T}_{\alpha}$ predominance in glycophorin, together with its $\mathrm{N}$-glycan, did cause binding, a clear case of the importance of clustering (Table 1). Testing this glycoprotein prior to and after desialylation and preferential degalactosylation of the $\mathrm{N}$-glycan also revealed that $\alpha 2-3$-sialylation of core 10 -glycan structures reduced the binding capacity (Table 1). This modification of free LacNAc has only a slightly negative effect on the affinity [18]. Thus, testing pairs of the sialo-/asialoglycoproteins with $\mathrm{N}$-glycan sialylation in $\alpha 2-3$ position are not expected to yield markedly different results. However, the removal of $\alpha 2-6$ sialylation should enhance reactivity.

The respective experiments are in accord with the assumed importance of the linkage type of sialylation and also an influence of the branching on the binding affinity (Table 1 ). The presence of $\alpha 2-6$ sialylation in the branches can impair reactivity, even switching off binding for fetuin, where this epitope resides in the $\alpha 1-3$ arm and in part also in the $\alpha 1-6$ arm, and drastically decreasing the reactivity for human $\alpha_{1}$-acid glycoprotein (Table 1 ). However, the case of porcine thyroglobulin precludes generalization. Due to its B-type/LacdiNAc termini in the $\alpha 1-6$ arm bovine lactoferrin maintained some reactivity relative to its desialylated form. Because the degree of branching increases from human asialolactoferrin to $\alpha_{1}$-acid glycoprotein (orosomucoid) from bi- to tetraantennary $N$-glycans, branching appears to correlate positively with reactivity for $\mathrm{N}$-glycans when presented on a protein backbone. We next tested the relative potency of glycoproteins to reduce the binding of galectin-3 using bovine asialolactoferrin with its several terminal structures for establishing the matrix. Significant inhibition was determined with certain glycoproteins rich in LacNAc termini and also the histo-blood group B-structure (Table 2). Two glycoproteins with Gal $\alpha 1-4$ Gal (E) and GalNAcß1-4Gal (S), i.e. the bird nest asialoglycoprotein and the Tamm-Horsfall urinary glycoprotein (THGP), appeared prominently 
Table 2

Inhibitory potency of various gps on binding of hGal-3 (125 ng/50 $\mu \mathrm{l})$ to a II-containing gp (bovine asialolactoferrin, $250 \mathrm{ng} / 50 \mu \mathrm{l}){ }^{\text {a }}$

\begin{tabular}{|c|c|c|}
\hline Inhibitor (terminal epitope) ${ }^{\mathrm{b}}$ & Quantity leading to 50\% inhibition (ng) & Relative potency \\
\hline \multicolumn{3}{|l|}{ Multi-antennary Galß1-4GlcNAc (II) gps } \\
\hline Porcine thyroglobulin ( $\alpha 2-3 / 6$ sialyl $\mathbf{~ m I I})$ & 100.0 & $6.8 \times 10^{3}$ \\
\hline Porcine asialothyroglobulin (mII) & 200.0 & $3.4 \times 10^{3}$ \\
\hline Human asialo $\alpha_{1}$-acid gp (mII) & 300.0 & $2.3 \times 10^{3}$ \\
\hline Bird nest asialo gp ( $\mathbf{E}$, iII, $\left.\mathbf{T}_{\boldsymbol{\alpha}}\right)$ & $600.0^{\mathrm{d}}$ & $1.1 \times 10^{3}$ \\
\hline THGP Sd $\left(\mathrm{a}^{+}\right)$W. M. (S, ilI $)$ & 1500.0 & $4.5 \times 10^{2}$ \\
\hline Asialo THGP Sd $\left(\mathrm{a}^{+}\right)$W. M. (S, iII $)$ & 2000.0 & $3.4 \times 10^{2}$ \\
\hline Human asialolactoferrin (mII, iII, Le $\mathbf{~}^{\mathbf{x}}$ ) & 2000.0 & $3.4 \times 10^{2}$ \\
\hline Bovine asialolactoferrin (mII, B, LacdiNAc) & 8000.0 & 85.5 \\
\hline Bovine asialo $\alpha_{1}$-acid gp (mII) & $>1388.9(47.1 \%)^{\mathrm{e}}$ & - \\
\hline Asialofetuin ( $\left.\mathrm{mII} / \mathbf{I}, \mathbf{T}_{\boldsymbol{\alpha}}\right)$ & $>1388.9(38.2 \%)$ & - \\
\hline Pneumococcus type 14 polysaccharide (ill/Lac) & $>1388.9(33.9 \%)$ & - \\
\hline Human $\alpha_{1}$-acid gp ( $\alpha 2-3 / 6$ sialyl mII $)$ & $>1388.9(22.8 \%)$ & - \\
\hline Bovine lactoferrin ( $\alpha 2-6$ sialyl mII, B, LacdiNAc) & $>2777.8(13.0 \%)$ & - \\
\hline Bovine $\alpha_{1}$-acid gp (sialyl mII ) & $>1388.9(4.9 \%)$ & - \\
\hline Fetuin $(\alpha 2-3 / 6$ sialyl mII/I, sialyl/disialyl $\mathbf{T})$ & $>1388.9(0.0 \%)$ & - \\
\hline \multicolumn{3}{|l|}{ Histo-blood group precursor (equivalent) gps } \\
\hline Cyst Beach P-1 (I/II) & 1800.0 & $3.8 \times 10^{2}$ \\
\hline Cyst OG $10 \% 2 x \mathrm{ppt}(\mathbf{I} / \mathbf{I I})$ & 2000.0 & $3.4 \times 10^{2}$ \\
\hline Cyst Tij $20 \%$ of second $10 \%\left(\mathbf{B}_{\mathrm{h}}>\mathbf{I} / \mathbf{I I}\right)$ & 3000.0 & $2.3 \times 10^{2}$ \\
\hline Cyst MSS 1st Smith degraded (I/II) & $8000.0^{\mathrm{d}}$ & 85.5 \\
\hline Cyst Mcdon P-1 (I/II) & $>1388.9(21.8 \%)$ & - \\
\hline Hog gastric mucin \#14 (A, II on core 2 and I-active $O$-glycans) & $>1388.9(11.9 \%)$ & - \\
\hline Hog gastric mucin \#21 (II on core 2 and I-active $O$-glycans) & $>1388.9(11.5 \%)$ & - \\
\hline Cyst Tighe P-1 (I/II) & $>1388.9(2.8 \%)$ & - \\
\hline \multicolumn{3}{|l|}{$\boldsymbol{T}$, Tn-containing gps } \\
\hline Human asialoglycophorin $\left(\mathbf{T}_{\boldsymbol{\alpha}}, \mathrm{Tn}, \mathrm{mIIl} \mathbf{b} / \mathbf{f}\right)$ & 2000.0 & $3.4 \times 10^{2}$ \\
\hline Human glycophorin (sialyl $\mathbf{T}_{\boldsymbol{\alpha}}, \mathrm{Tn}, \alpha 2-6$ sialyl mIIb/f) & $>2777.8(14.4 \%)$ & - \\
\hline Asialo PSM (Tn, $\left.\mathbf{T}_{\boldsymbol{\alpha}}, \mathbf{A}, \mathbf{A}_{\mathrm{h}}, \mathbf{H}\right)$ & $>555.6(2.0 \%)$ & - \\
\hline \multicolumn{3}{|l|}{ Histo-blood group ABH-active gps } \\
\hline Cyst $19\left(\mathbf{B}_{\mathrm{h}}>\mathbf{L e}^{\mathbf{b}}, \mathbf{L e}^{\mathbf{y}}\right)$ & 3000.0 & $2.3 \times 10^{2}$ \\
\hline Cyst Beach phenol insoluble $\left(\mathbf{B}_{\mathrm{h}}>\mathbf{L e}^{\mathbf{b}}, \mathbf{L e}^{\mathbf{y}}\right)$ & 4000.0 & $1.7 \times 10^{2}$ \\
\hline Hog gastric mucin \#4 ( $\mathbf{A}_{\mathbf{h}}, \mathbf{H}$ on core 2 and I-active 0 -glycans) & $>1388.9(34.8 \%)$ & - \\
\hline Hog gastric mucin \#9 ( $\mathbf{A}_{\mathbf{h}}, \mathbf{H}$ on core 2 and I-active 0 -glycans) & $>1388.9(26.0 \%)$ & - \\
\hline Cyst Mcdon $\left(\mathbf{A}_{\mathbf{h}}>\mathbf{L e}^{\mathbf{b}}, \mathbf{L e}^{\mathbf{y}}\right)$ & $>1388.9(20.7 \%)$ & - \\
\hline \multicolumn{3}{|l|}{ Lewis $^{a}$ - and Lewis $^{b}$-active gps } \\
\hline Cyst N-1 Le $20 \% 2 x\left(\mathbf{L e}^{\mathbf{a}}, \mathbf{L e}^{\mathbf{x}}\right)$ & $>1388.9(21.0 \%)$ & - \\
\hline Cyst Tighe phenol insoluble ( $\left.\mathbf{H}, \mathbf{L e}^{\mathbf{a}}, \mathbf{L e}^{\mathbf{b}}, \mathbf{L e}^{\mathbf{x}}, \mathbf{L e}^{\mathbf{y}}\right)$ & $>1388.9(10.0 \%)$ & - \\
\hline Asialo HOC $350\left(\mathbf{L e}^{\mathrm{a}}\right)$ & $>138.9(1.9 \%)$ & - \\
\hline \multicolumn{3}{|l|}{ Saccharides } \\
\hline Tri-II & 8316.0 & 82.3 \\
\hline Galß1-4GlcNAc (II) & $684,600.0^{\mathrm{d}}$ & 1.0 \\
\hline Gal & $2,000,000.0$ & 0.3 \\
\hline GalNAc & $2,000,000.0$ & 0.3 \\
\hline
\end{tabular}

a The inhibitory activity is expressed as the amount of inhibitor leading to $50 \%$ inhibition of the control lectin binding. Total volume was $50 \mu$.

b See footnote of Table 1.

c Relative potency (RP) = quantity of Galß1-4GlcNAc (II) required for $50 \%$ inhibition (taken as 1.0 )/quantity of sample required for $50 \%$ inhibition.

d Extrapolation.

e The inhibitory potency of inactive gps is expressed as the maximum amount of glycans tested that yield inhibition (in parenthesis) below $50 \%$. Other glycans that did not reach

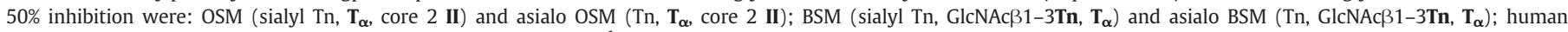
asialoagalactoglycophorin $\left(\mathbf{T}_{\boldsymbol{\alpha}}, \mathbf{T n}\right)$; cyst 14 phenol insoluble $\left(\mathbf{A}_{\mathbf{h}}>\mathbf{L} \mathbf{e}^{\mathbf{b}}\right.$, Le $\left.\mathbf{L}^{\mathbf{y}}\right) ; \operatorname{HOC} 350$ (sialyl $\left.\mathbf{L e}^{\mathbf{a}}\right)$.

on this list (Table 2). In order to elucidate whether these epitopes are key contact sites for the lectin we next investigated a series of mono-, di- and oligosaccharides for inhibitory capacity.

\subsection{Free glycans as ligands}

Bovine asialolactoferrin was maintained as ligand-bearing matrix, and the free sugar compound tested was added to the lectincontaining solution to compete with the immobilized glycoprotein's glycans for entry into the lectin site. The two disaccharides (E) and (S) were only weakly active (Table 3). Evidently, other disaccharides such as (T), its extended version T $\beta 1-4 \mathrm{~L}$ or the Gal $\alpha 1-3$-capped LacNAc (B active II) were also rather weak inhibitors. In comparison, branching yielded enhanced inhibition (Table 3). Chain elongation, too, was effective toward this end (Table 3). This set of experiments thus further solidifies the notion that the local density of glycan branches in a glycoprotein is a modulator for binding to this type of natural glycoconjugate. The actual contact can apparently be made to II/I structures, which can be extended to histo-blood group $A B H$ epitopes, as well as to LacdiNAc and $\mathrm{T}_{\alpha}$. To explain in structural terms the reactivity of galectin-3 in solution to these epitopes, we next performed computational modeling.

\subsection{Computational interaction analysis}

In docking with HADDOCK version 2.1 [37,38], both the lectin and its carbohydrate ligand can be treated as flexible. This procedure enables us to detect any ligand-dependent adaptations, especially 
with oligosaccharides as ligands. At the same time, we were able to collect comprehensive statistical information on the range of interactions and their dynamics. In all six cases studied, the formation of the lectin-ligand complex proceeded without any notable structural deviation of the carbohydrate ligand from its low-energy conformation in the free state. On the protein side, no major conformational

Table 3

Inhibitory potency of various mono- and oligosaccharides on binding of hGal-3 ( $125 \mathrm{ng} / 50 \mu \mathrm{l}$ ) to a II-containing gp (bovine asialolactoferrin, $250 \mathrm{ng} / 50 \mu \mathrm{l})$ a $^{\mathrm{a}}$

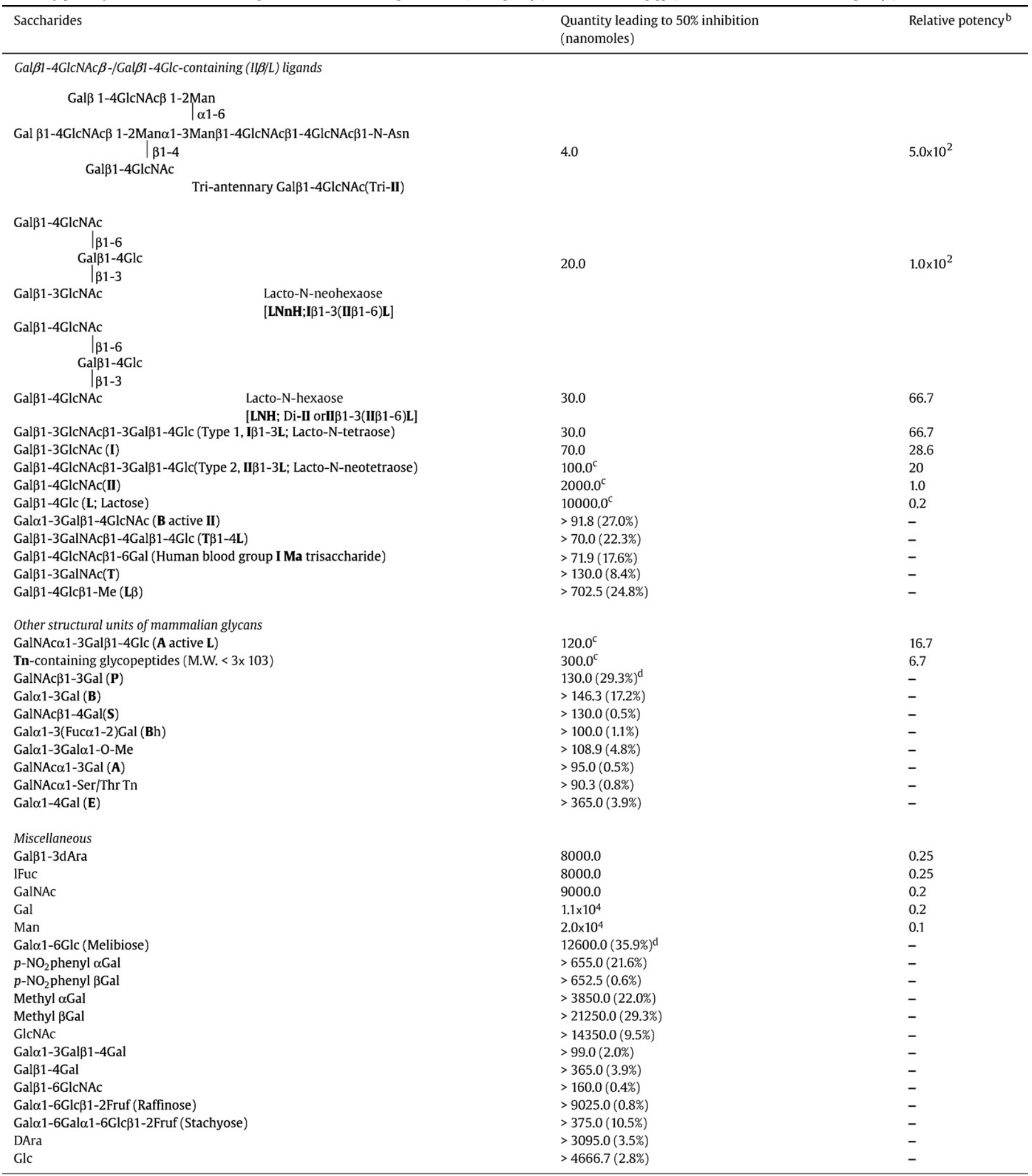

${ }^{a}$ The inhibitory activity is expressed as the amount of inhibitor leading to $50 \%$ inhibition of the control lectin binding. Total volume was $50 \mu l$.

${ }^{b}$ Relative potency = quantity of Gal $\beta 1-4$ GlcNAc (II) required for $50 \%$ inhibition is taken as 1.0 /quantity of sample required for $50 \%$ inhibition.

${ }^{\mathrm{c}}$ Extrapolated value.

${ }^{\mathrm{d}}$ The inhibitory potency of inactive saccharides is expressed as the maximum amount of sugars tested that yield inhibition (in parenthesis) below $50 \%$. 


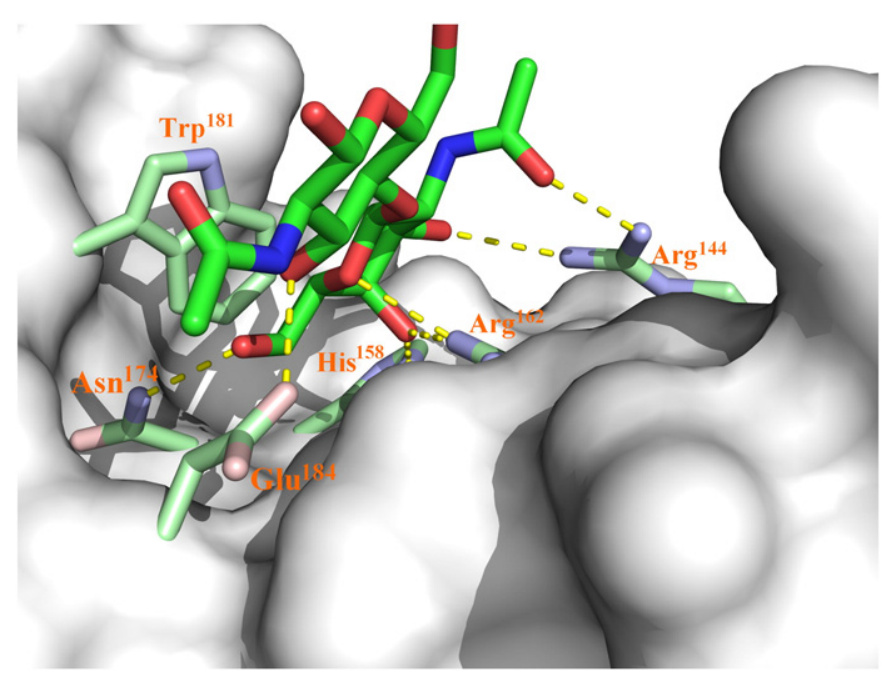

Fig. 2. Model of the interaction of hGal-3 with LacdiNAc. The lectin site of hGal-3 is shown in surface representation with key side chains in sticks. Hydrogen bonds are indicated in yellow. Note that this is only one of the panels of models and that the dynamics of the interaction can be viewed in the corresponding movie available at http://www.nmr.chem.uu.nl/ mkrzemin/hgal3-dNAL_music.mpg or available under http://www.nmr.chem.uu.nl/haddock/movies/hgal3.html.

changes seemed to occur in the binding site. As illustration for possible lectin-ligand contacts formed, a model of the complex of hGal-3 with LacdiNAc is shown in Fig. 2. A synopsis of the energetic contribution of the various amino acids involved in the interaction using a set of ten energetically minimized structures is available as Supplementary material (Tables S1-S3). In order to reflect the dynamic interplay with the inherent degree of contact flexibility in solution we performed a statistical analysis of the patterns of interactions of a large population of docking models, rather than to concentrate on a few examples. The validity of this approach was tested by comparing the crystal structure with bound Gal $\beta 1-4 \mathrm{GlcNAc}$ (II) to the computational data obtained for an ensemble of 1000 models. As summarized in Table 4, it is satisfying to note that, in addition to the set of the four imposed hydrogen-bond contacts, the interaction pattern observed in the crystal structure was reproduced, i.e. hydrogen bonds involving Glu184 and Arg162. These features were nearly invariably seen in all the models. At decreased frequency, possibly reflecting a certain degree of flexibility in solution, additional contacts were picked up at distances from $3.5 \AA$ Apward (Table 4). Hereby having validated this statistical approach, we proceeded to analyze docking models for other biologically relevant di- and tetrasaccharides. Contact statistics for three disaccharides are provided in Table 5 and for the two histo-blood group tetrasaccharides in Table 6 .

The interaction dynamics are visualized in the movies available at http://www.nmr.chem.uu.nl/haddock/movies/hgal3.html. As shown, the additional $\mathrm{N}$-acetyl group of LacdiNAc can engage in a hydrogen bond with $\operatorname{Arg} 144$ in about one third of the 1500 docking models (Table 5). Despite a repulsive Coulomb energy term originating from Arg186 in the energetically minimized complex (Supplementary material, Table S1) the interactions listed in Table 5 and seen to arise in the respective movie can serve to explain the known ligand properties. The switch to a $\beta 1-3$ linkage augments the interaction profile for LacNAc (I) vs LacNAc (II). The GlcNAc/GalNAc substitution reduced its extent (Table 5), as also reflected in the Coulomb energy terms (Supplementary material, Table S2). These differences can rationalize the disparate inhibitory capacities for the disaccharides listed in Table 3. In the two histo-blood group tetrasaccharides, the $\alpha 1-$ 3 extension is responsible for an increase in the number of contacts, with a ligand-type-specific pattern due to the presence of the additional $\mathrm{N}$-acetyl group (Table 6). The statistical approach reveals a hydrogenbond network involving Arg144, Lys176 and Trp181 (Fig. 3 and respective movie). As seen in the respective movies and Supplementary material, Table S3, the $\alpha 1-2$-linked fucose moiety is of a lesser importance for the interaction. The B-type tetrasaccharide is also found

Table 4

Statistical analysis of intermolecular interactions between hGal-3 and $\mathrm{N}$-acetyllactosamine. ${ }^{\mathrm{a}}$

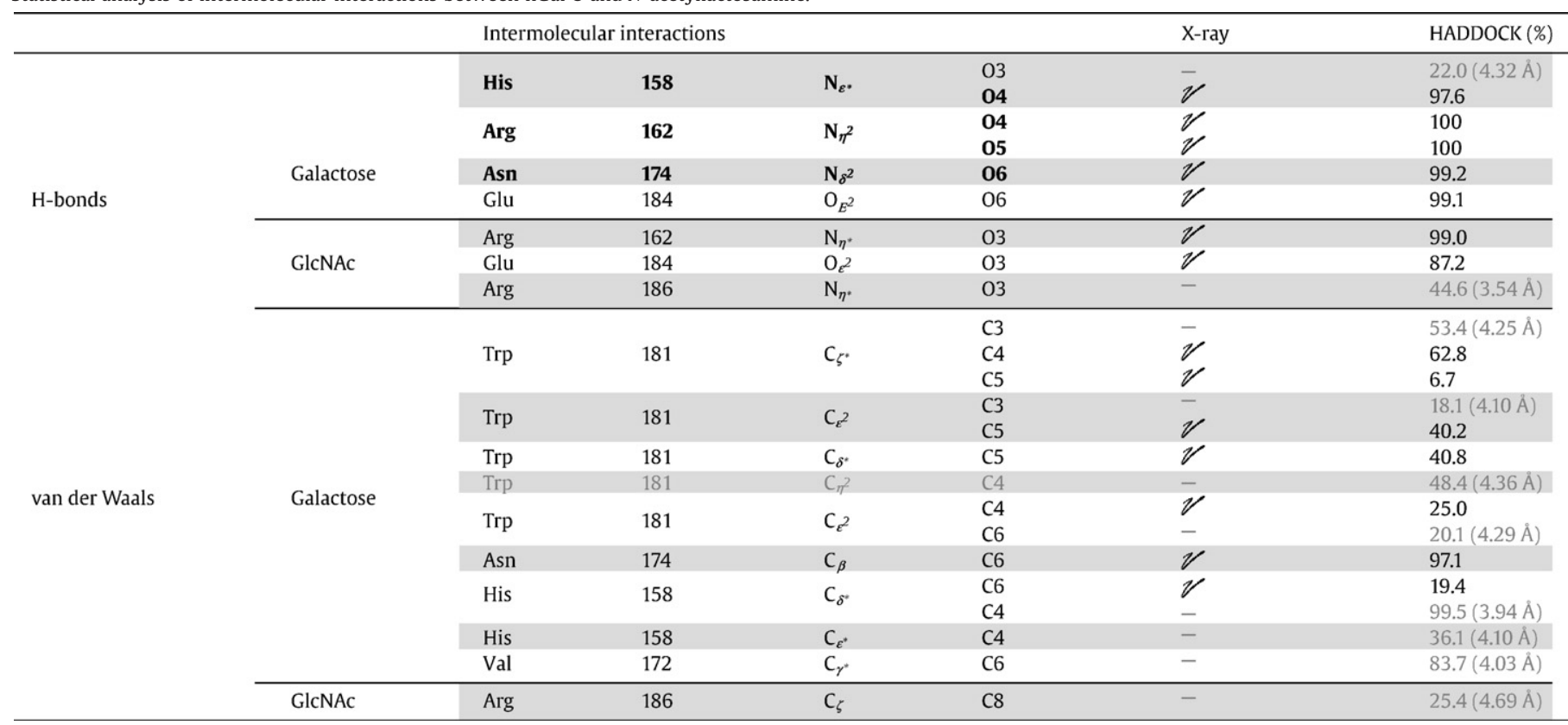

\footnotetext{
a Contacts observed in the crystal structure are compared to those estimated from 1000 docking models obtained with HADDOCK (imposed restraints are indicated in bold font).
}



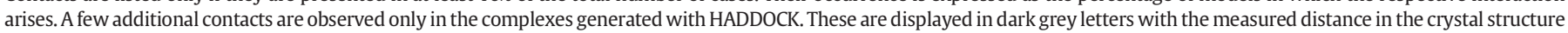
specified between brackets. 
Table 5

Statistical analysis of interactions of hGal-3 with LacdiNAc, TF and LacNAc-I.

\begin{tabular}{|c|c|c|c|c|c|c|c|c|}
\hline & & \multicolumn{3}{|c|}{ Galectin-3 } & \multirow[t]{2}{*}{ Ligand atom } & $\frac{\text { LacdiNAc (\%) }}{\text { GalNAc-GlcNAc }}$ & $\frac{\mathrm{TF}(\%)}{\text { Gal-GalNAc }}$ & $\frac{\text { LacNAc-I (\%) }}{\text { Gal-GlcNAc }}$ \\
\hline \multirow[t]{15}{*}{ H-bonds } & Gal/GalNAc & Arg & 144 & $\mathrm{~N}_{\eta} *$ & & 33.6 & - & - \\
\hline & & His & 158 & $\mathrm{~N}_{\varepsilon} *$ & 04 & 99.9 & 95.9 & 98.2 \\
\hline & & Arg & 162 & $\mathrm{~N}_{\eta} *$ & 04 & 99.9 & 99.9 & 99.9 \\
\hline & & & & & 05 & 100.0 & 99.9 & 99.9 \\
\hline & & Asn & 174 & $\mathrm{~N}_{\delta} *$ & 06 & 96.0 & 99.0 & 98.7 \\
\hline & & Glu & 184 & $\mathrm{O}_{\varepsilon}^{*}$ & 06 & 84.9 & 87.5 & 96.7 \\
\hline & GlcNAc/GalNAc & Arg & 162 & $\mathrm{~N}_{\eta} *$ & $\mathrm{O} 3$ & 13.3 & 4.1 & 4.0 \\
\hline & & & & & 04 & 4.9 & 26.7 & 66.2 \\
\hline & & Glu & 165 & $\mathrm{O}_{\varepsilon} *$ & $\mathrm{O} 3$ & 70.8 & 0.0 & 8.6 \\
\hline & & & & & 04 & 0.0 & 4.3 & 35.8 \\
\hline & & & & & N2 & 10.3 & 0.0 & 0.0 \\
\hline & & Glu & 184 & $\mathrm{O}_{\varepsilon} *$ & $\mathrm{O} 4$ & 0.0 & 0.2 & 28.7 \\
\hline & & & & & N2 & 12.3 & 10.0 & 8.6 \\
\hline & & Arg & 186 & $\mathrm{~N}_{\eta} *$ & $\mathrm{O} 3$ & 10.5 & 0.0 & 0.0 \\
\hline & & & & & 04 & 0.0 & 0.7 & 30.5 \\
\hline \multirow[t]{23}{*}{ van der Waals } & Gal/GalNAc & Arg & 162 & $\mathrm{C}_{\zeta}$ & $\mathrm{C} 1$ & 21.7 & 2.4 & 13.4 \\
\hline & & & & & $\mathrm{C} 2$ & 3.1 & 1.5 & 26.3 \\
\hline & & Trp & 181 & $C_{\zeta *}$ & $\mathrm{C} 3$ & 53.2 & 62.1 & 24.9 \\
\hline & & & & & $\mathrm{C} 4$ & 66.5 & 47.9 & 39.5 \\
\hline & & & & & C6 & 3.8 & 8.7 & 11.0 \\
\hline & & Trp & 181 & $\mathrm{C}_{\delta} *$ & C6 & 9.2 & 2.9 & 16.9 \\
\hline & & Trp & 181 & $\mathrm{C}_{\varepsilon} *$ & $\mathrm{C} 3$ & 16.6 & 17.6 & 5.3 \\
\hline & & & & & $\mathrm{C} 4$ & 32.0 & 6.9 & 10.9 \\
\hline & & Trp & 181 & $\mathrm{C}_{\eta} *$ & $\mathrm{C} 3$ & 9.2 & 25.1 & 5.3 \\
\hline & & & & & $\mathrm{C} 4$ & 54.5 & 53.7 & 39.6 \\
\hline & & His & 158 & $\mathrm{C}_{\delta} *$ & $\mathrm{C} 4$ & 87.9 & 99.3 & 86.7 \\
\hline & & & & & $\mathrm{C} 5$ & 21.7 & 14.1 & 0.0 \\
\hline & & & & & C6 & 7.0 & 33.1 & 24.8 \\
\hline & & His & 158 & $\mathrm{C}_{\varepsilon} *$ & $\mathrm{C} 4$ & 7.3 & 37.4 & 17.0 \\
\hline & & & & & $\mathrm{C} 5$ & 24.4 & 15.5 & 13.1 \\
\hline & & Asn & 174 & $\mathrm{C}_{\beta}$ & C6 & 75.8 & 85.9 & 68.9 \\
\hline & & Val & 172 & $\mathrm{C}_{\gamma}^{*}$ & C6 & 68.9 & 76.8 & 64.6 \\
\hline & & Trp & 181 & $\mathrm{C}_{\varepsilon}^{*}$ & C6 & 19.0 & 16.1 & 23.5 \\
\hline & GlcNAc/GalNAc & Glu & 165 & $\mathrm{C}_{\delta}$ & $\mathrm{C} 6$ & 0.0 & 1.8 & 24.7 \\
\hline & & Trp & 181 & $\mathrm{C}_{\delta} *$ & $\mathrm{C} 8$ & 0.0 & 0.3 & 29.5 \\
\hline & & Glu & 184 & $\mathrm{C}_{\delta}$ & C6 & 0.0 & 12.7 & 1.1 \\
\hline & & & & & $\mathrm{C} 8$ & 9.5 & 34.3 & 10.3 \\
\hline & & Arg & 186 & $\mathrm{C}_{\zeta}$ & $\mathrm{C} 3$ & 12.2 & 0.0 & 0.0 \\
\hline
\end{tabular}

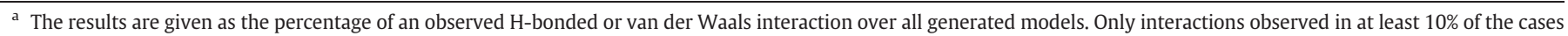
are specified. Bold numbers indicate the interactions of a given ligand that are significantly higher than the same type of interaction for the other two ligands.

to gain deeper entry into the binding site than the A-type glycan. These models provide an interaction profile for hGal-3 that can be used for rational drug design $[45,59]$ and comparative considerations to other members in this lectin family. In this respect, the distinct expression profile of this lectin also warrants study, prompting us to perform computational promoter analysis.

\subsection{Computational promoter analysis}

In order to provide insights into the organization of the potentially regulatory sequence motifs in the proximal promoter region, another measure of sequence-activity comparison, two search algorithms were applied. They will spot presence of putative binding sites for transcription factors based on stringency criteria strictly kept constant to enable comparison. A series of potential hits was compiled (for a complete listing, see Table S4 in Supplementary material). To test the assumption for non-uniform patterns, this panel of sites satisfying formal sequence criteria was compared with the results of corresponding analysis for the genes of the proto-type galectins-1, -2 and -7 under identical conditions. Indeed, a series of cases of intrafamily diversification was detected. Table 7 summarizes the unique features, with nine sites exclusively detected for hGal-3.
Sequence diversification between galectin genes is thus markedly operative in the proximal promoter region.

\section{Discussion}

In this study we have investigated the interaction of hGal-3 with its carbohydrate ligands on the level of glycoproteins. The results reveal a notable degree of selectivity for binding of hGal-3 to natural glycoproteins with $\mathrm{N}$-glycan (but not core $2 \mathrm{O}$-glycan) branching and clustering of core $1 \mathrm{O}$-glycans as positive factors. Contrary to previous work with $\beta$-galactoside-specific plant lectins such as ricin in this assay system [60], the mere presence of a hGal-3-reactive epitope in the glycan chain is not sufficient for binding to the glycoprotein. When therefore presented on core 2 branches of hog gastric mucin, the Atype histo-blood group determinant only has low avidity for the lectin. This feature of hGal-3 is in clear contrast to the strong reactivity of rat galectin-4's N-domain and galectin-5 with this mucin $[48,52,61]$. Further discriminatory features include the strong reactivity of the Le ${ }^{\mathrm{a}}$ epitope to both mentioned lectins and that of $T_{n}$ clusters to galectin- $4[48,52,61]$. Looking at the two already tested chicken proto-type galectins, which are closely related to human galectin-1 $[58,62,63]$, their lack of reactivity with asialoglycophorin highlights another marked difference on the level of glycoproteins 
Table 6

Statistical analysis of interactions of hGal-3 with histo-blood group A/B-tetrasaccharides. ${ }^{\text {a }}$

\begin{tabular}{|c|c|c|c|c|c|c|c|}
\hline & Resic & & & Monosaccha & & A-type (\%) & B-type (\%) \\
\hline \multirow[t]{6}{*}{ H-bonds } & Asn & 160 & $\mathrm{O}_{\delta}{ }^{*}$ & Gal & $\mathrm{O} 4$ & 0.8 & 21.8 \\
\hline & Glu & 184 & $\mathrm{O}_{\varepsilon}{ }^{*}$ & Glc & $\mathrm{O} 2$ & 59.2 & 32.2 \\
\hline & Arg & 144 & $\mathrm{~N}_{\eta}{ }^{*}$ & GalNAc/Gal & 07 & 32.2 & - \\
\hline & & & & & $\mathrm{O} 3$ & 0.2 & 33.0 \\
\hline & Lys & 176 & $\mathrm{~N}_{\zeta}$ & GalNAc/Gal & O6 & 19.8 & 44.8 \\
\hline & Trp & 181 & $\mathrm{~N}_{\varepsilon}{ }^{*}$ & & & 85.0 & 43.5 \\
\hline \multirow[t]{3}{*}{ van der Waals } & His & 158 & $\mathrm{C}_{\varepsilon}^{*}$ & GalNAc/Gal & $\mathrm{C} 1$ & 41.8 & 94.0 \\
\hline & & & & & $\mathrm{C} 2$ & 1.2 & 35.0 \\
\hline & Asn & 160 & $\mathrm{C}_{\gamma}$ & GalNAc/Gal & $\mathrm{C} 8$ & 78.0 & - \\
\hline
\end{tabular}

a The results are given as the percentage of an observed H-bonded or van der Waals interaction over all generated models. Only interactions observed in at least $10 \%$ of the cases are specified.

[39,47]. Although these lectins together with hGal-3 can interact with the $T_{\beta}$ determinant in the context of the GM1 pentasaccharide [64], the 150 -glycans on asialoglycophorin fail to form a platform for binding the proto-type galectins [39]. Obviously, a route towards selectivity for glycoproteins is the way glycan epitopes are presented spatially, as is the case for ganglioside GM1 in microdomains on the membrane [65]. Clustered presentation of the sugar headgroup of gangliosides, in microdomains together with glycoproteins such as integrins, can thus form high-affinity aggregates [66], provided there are no spatial restrictions to letting the glycan chains adopt the conformer suitable for binding $[53,64,67]$. Our experiments with natural glycoproteins presented on a surface thus prove instrumental to decipher rules of physiological selectivity, considering spatial parameters. A closer look on topological aspects of ligand contact is provided by the docking analysis.

In general, a common property of galectins is the binding of distinct low-energy conformers of the carbohydrate countereceptor. Previous rigid-body docking studies on mammalian galectin-3, without allowing full flexibility on both sides, had indicated that no deviations from an energetically privileged position are required $[68,69]$. This also holds true for binding of histo-blood group tri- and tetrasaccharides in crystals to a fungal galectin (PDB codes 1ULD, 1ULE, and 1ULF), the E. coli enterotoxin and its hybrid with cholera toxin (202L, 3EFX), a Streptococcus pneumoniae virulence factor (2J1U) and the Norwalk virus (2ZL7). Our results from flexible docking extend the respective data basis significantly. We present a view on the individual energy contributions in the complex, derived from energy-minimized models after allowing mutual flexibility. Going beyond the static view, we have introduced a statistical approach to the analysis of the dynamics of interactions from
HADDOCK-derived data on large ensembles of docking models. It gives net advantages compared to common, energy-based-only analysis approaches, since it reflects the probability of a given interaction to exist, provided the interaction space has been sufficiently sampled. It also offers the possibility to better appreciate ligand flexibility in the binding pocket, which facilitates transient contacts to certain amino acids.

Our results provide explanations for distinct specificity traits, uncovering the importance of Arg144 for LacdiNAc binding (Asn is at this place in galectin- 1 , which is only weakly reactive with this disaccharide in a cell assay [22]). Also, the free enthalpy gains by 2.75 and $8.44 \mathrm{kcal} / \mathrm{mol}$ by adding the Fuc and the GalNAc units to the $\beta$ galactoside core, measured by titration calorimetry at 279.6 or $280.4 \mathrm{~K}$ [17], can be rationalized by the presented interaction analysis. Of note, the favorable changes in the protein's overall conformational entropy upon ligand binding add to the overall thermodynamic balance [70]. The detailed description of the extended binding site and the interaction profile of flexible lectin/ligand pairs refine the structural basis in order to inspire the rational design of substitutions in synthetic inhibitors, thereby opening the route to the exploitation of the sequence differences between galectins for the benefit of reducing intrafamily cross-reactivity. This modeling approach and the derived structural models will thus be helpful in automated screening for glycomimetics such as (glyco)peptides [71] and estimating their relative potencies.

In addition to delineating intrafamily differences in carbohydrate specificity the definition of the regulatory mechanisms underlying the distinct gene expression profiles, e.g. also with upregulation in inflammation [72,73], is a further challenge. Using two current search algorithms we have mapped the proximal promoter region with
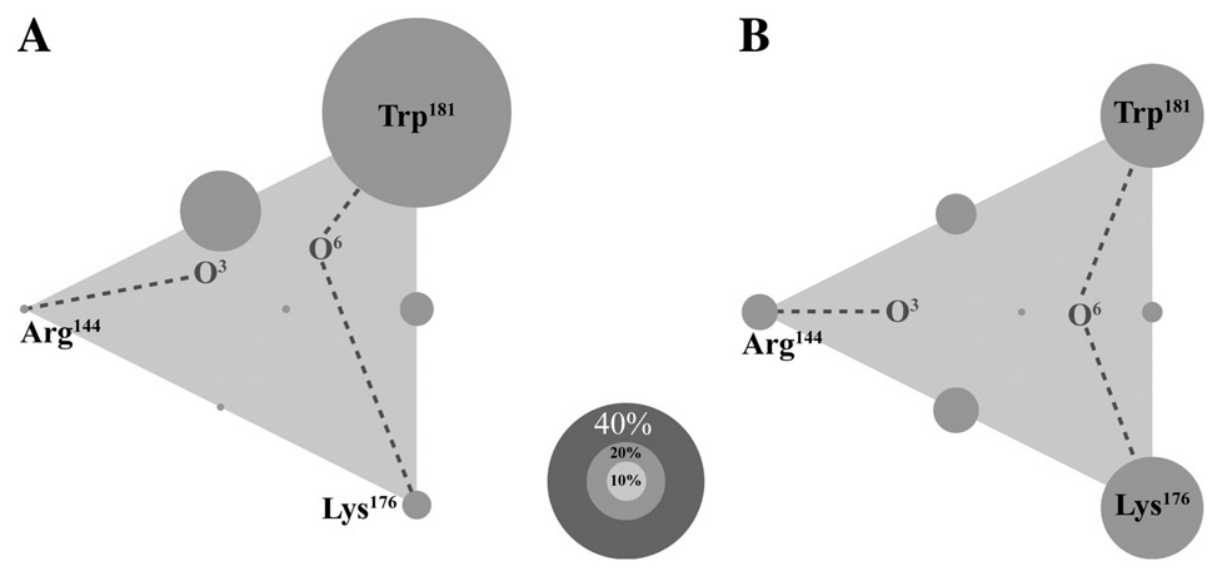

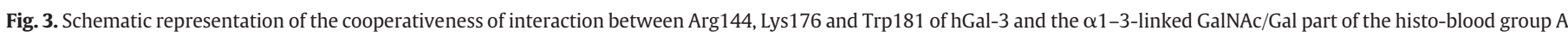

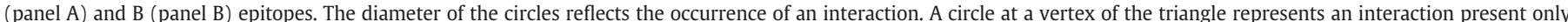

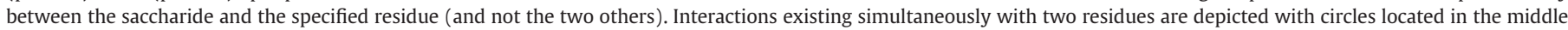

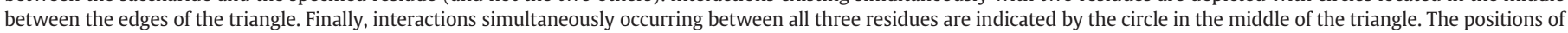
the $\mathrm{O}^{3}$ and $\mathrm{O}^{6}$ oxygen atoms are shifted to reflect their interaction preferences. 
Table 7

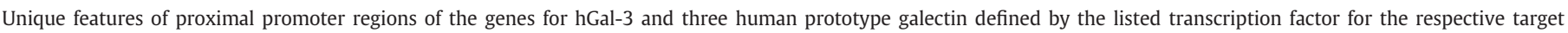
sequence. $^{\mathrm{a}}$

\begin{tabular}{|c|c|c|}
\hline Galectin & Presence & Absence \\
\hline hGal-3 & AP-2, c-Ets-1 (p54), E2F, HNF-1 $\alpha$, Lmo2-complex, Olf-1, Pax-6, POU3F1 (Oct-6, Tst-1), RFX1 & Lyf-1, S8 (Prx-2) \\
\hline hGal-1 & Elk-1 (TCF-A), NF-Y, TGIF & Evi-1, Msx-1 \\
\hline hGal-2 & AhR:Arnt, HLF, HNF-4 $\alpha 2$ (COUP-TF), VBP & - \\
\hline hGal-7 & CP2, FoxD3, FoxI1 (HFH3), p300, ZEB (AREB6) & Pbx-1a \\
\hline
\end{tabular}

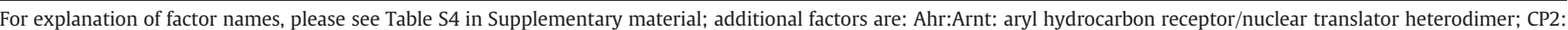

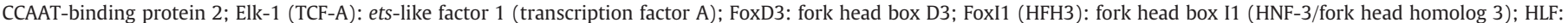

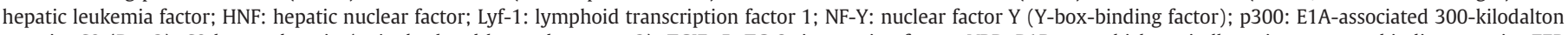

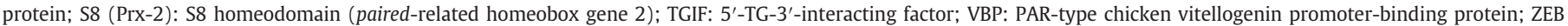
(AREB6): zinc finger E-box-binding protein (Atp1a1 regulatory element binding protein 6).

a In each case the region from 2000 bp upstream to $150 \mathrm{bp}$ downstream relative to the gene's transcription start was chosen as proximal promoter region. Only those putative binding motifs are listed which are uniquely present or absent when compared with the proximal promoter regions of the other three galectins.

respect to the presence of putative binding sites for transcription factors. Detailed comparisons to previous, analyses reporting the presence of nine or 49 motifs [74,75], revealed a low degree of overlap. Only three GC-boxes from nine motifs and three GC-boxes, the GATA-3, Lmo2 and c-Ets-1 sites, respectively, were shared. This result teaches the lesson that one should be cautious in considering bioinformatics sequence classification as a guideline for functional studies. This conclusion is underscored by the differences in ascribing RUNX-binding properties to distinct promoter sequences. Such a site was described to be close to the transcription start [75] or, as shown herein, markedly downstream. Because RUNX1/2 are known to upregulate galectin-3 gene expression in gliomas and pituitary tumors [76,77], the actual nature of the apparently active promoter region can now be classified following the derived information. The positivity for Lmo2 of mononuclear cells (specifically microglia and Kupffer cells) reported previously [78] is a promising case for further study, as is the presence of the other binding sites unique for hGal-3 or shared by the two bioinformatics analyses, for example GATA-3, the master regulator for differentiation of T helper 2 cells [79]. That c-Ets1 was reported to positively regulate the expression of two glycosyltransferases with impact on cell reactivity for galectins, i.e. $\mathrm{N}$-acetylglucosaminyltransferase-V crucial for the $\beta 1-6$ branch and $\beta 1-4$-galactosyltransferase- $\mathrm{V}[80,81]$, even points to the possibility for an orchestration of expression of the lectin with ligandmodulating enzymes. A glycogene microarray on wound re-epithelialization in cornea also pointed to a co-expression with an enzyme involved in I synthesis ( $\beta 3$ GalT5), the $\mathrm{T}$ synthase for $\mathrm{T}_{\alpha}$ synthesis and an enzyme responsible for adding a branch to the $\alpha 1-3$-arm of the $N$ glycan core (GnT-IVb) [82]. Case studies on growth regulation of tumor cells by galectin-1 attest the validity of this concept for a functional co-regulation $[83,84]$. Of note, galectin-3 production is additionally known to be modulated post-transcriptionally $[28,85]$.

In conclusion, the testing of natural glycoproteins reveals distinct preferences for hGal-3. Branching of $\mathrm{N}$-glycans and high density of core 10 -glycans are favorable factors. The presence of $\alpha 2-6$ sialylation in $\mathrm{N}$-glycans and the core 2 in $\mathrm{O}$-glycans can decrease avidity, even if epitopes suited as ligands are present. The HADDOCKbased modeling, allowing for both lectin and ligand flexibility, resulted in a detailed description of the interaction profile and its dynamics, relevant to explain relative affinities and to inspire substitutions for drug design. Computer-based promoter analysis directed the attention to Lmo2 for expression in the monocytemacrophage lineage and to c-Ets- 1 for potential of co-regulation with two glycosyltransferases initiating and extending the $\beta 1-6$ branch of $N$-glycans.

\section{Acknowledgements}

We are grateful for generous financial support by the Verein zur Förderung des biologisch-technologischen Fortschritts in der Medizin e. V. (Heidelberg, Germany), an EC Marie Curie research training network grant (contract no. MRTN-CT-2005-019561) and to EC funding for the GlycoHIT program, to L. Mantel for skillful technical assistance as well as to Drs. B. Friday, A. W. L. Nose and B. Tab for inspiring discussions. AMJJB acknowledges financial support from the Dutch Foundation for Scientific Research (NWO) through a VICI grant (no. 700.56.442). The eNMR project (European FP7 e-Infrastructure grant, contract no. 213010, www.enmr.eu), supported by the national GRID Initiatives of Italy, Germany and the Dutch BiG Grid project (Netherlands Organization for Scientific Research), is acknowledged for the use of web portals, computing and storage facilities.

\section{Appendix A. Supplementary data}

Supplementary data to this article can be found online at doi:10.1016/j.bbagen.2010.11.001.

\section{References}

[1] H.-J. Gabius (Ed.), The Sugar Code. Fundamentals of Glycosciences, Wiley-VCH, Weinheim, Germany, 2009.

[2] A. Villalobo, A. Nogales-González, H.-J. Gabius, A guide to signaling pathways connecting protein-glycan interaction with the emerging versatile effector functionality of mammalian lectins, Trends Glycosci. Glycotechnol. 18 (2006) 1-37.

[3] M.-K. Ho, T.A. Springer, Mac-2, a novel 32,000 Mr macrophage subpopulationspecific antigen defined by monoclonal antibodies, J. Immunol. 128 (1982) 1221-1228.

[4] T.J. Flotte, T.A. Springer, G.J. Thorbecke, Dendritic cell and macrophage staining by monoclonal antibodies in tissue sections and epidermal sheets, Am. J. Pathol. 111 (1983) 112-124.

[5] H.-J. Gabius, R. Brehler, A. Schauer, F. Cramer, Localization of endogenous lectins in normal human breast, benign breast lesions and mammary carcinomas, Virchows Arch. B 52 (1986) 107-115.

[6] M. Lohr, H. Kaltner, M. Lensch, S. André, F. Sinowatz, H.-J. Gabius, Cell-typespecific expression of murine multifunctional galectin-3 and its association with follicular atresia/luteolysis in contrast to pro-apoptotic galectins- 1 and -7 , Histochem. Cell Biol. 130 (2008) 567-581.

[7] B.J. Cherayil, S. Chaitovitz, C. Wong, S. Pillai, Molecular cloning of a human macrophage lectin specific for galactose, Proc. Natl. Acad. Sci. U. S. A. 87 (1990) 7324-7328.

[8] R.C. Hughes, Mac-2: a versatile galactose-binding protein of mammalian tissues, Glycobiology 4 (1994) 5-12.

[9] D.N.W. Cooper, Galectinomics: finding themes in complexity, Biochim. Biophys. Acta 1572 (2002) 209-231.

[10] T.K. van den Berg, H. Honing, N. Franke, A. van Remoortere, W.E.C.M. Schiphorst, F.-T. Liu, A.M. Deelder, R.D. Cummings, C.H. Hokke, I. van Die, LacdiNAc-glycans constitute a parasite pattern for galectin-3-mediated immune recognition, J. Immunol. 173 (2004) 1902-1907.

[11] R. Jin, A. Greenwald, M.D. Peterson, T.K. Waddell, Human monocytes recognize porcine endothelium via the interaction of galectin-3 and $\alpha$-GAL, J. Immunol. 177 (2006) 1289-1295.

[12] S. André, S. Kojima, N. Yamazaki, H. Fink, H. Kaltner, K. Kayser, H.-J. Gabius, Galectins- 1 and -3 and their ligands in tumor biology, J. Cancer Res. Clin. Oncol. 125 (1999) 461-474.

[13] J. Kopitz, C. von Reitzenstein, S. André, H. Kaltner, J. Uhl, V. Ehemann, M. Cantz, H.-J. Gabius, Negative regulation of neuroblastoma cell growth by carbohydratedependent surface binding of galectin- 1 and functional divergence from galectin-3, J. Biol. Chem. 276 (2001) 35917-35923. 
[14] B.N. Stillman, D.K. Hsu, M. Pang, C.F. Brewer, P. Johnson, F.-T. Liu, L.G. Baum, Galectin-3 and galectin-1 bind distinct cell surface glycoprotein receptors to induce cell death, J. Immunol. 176 (2006) 778-789.

[15] L.-G. Yu, N. Andrews, Q. Zhao, D. McKean, J.F. Williams, L.J. Connor, O.V. Gerasimenko, J. Hilkens, J. Hirabayashi, K.-i. Kasai, J.M. Rhodes, Galectin-3 interaction with Thomsen-Friedenreich disaccharide on cancer-associated MUC1 causes increased cancer cell endothelial adhesion, J. Biol. Chem. 282 (2007) 773-781.

[16] C.P. Sparrow, H. Leffler, S.H. Barondes, Multiple soluble $\beta$-galactoside-binding lectins from human lung, J. Biol. Chem. 262 (1987) 7383-7390.

[17] K. Bachhawat-Sikder, C.J. Thomas, A. Surolia, Thermodynamic analysis of the binding of galactose and poly- $N$-acetyllactosamine derivatives to human galectin3, FEBS Lett. 500 (2001) 75-79.

[18] N. Ahmad, H.-J. Gabius, H. Kaltner, S. André, I. Kuwabara, F.-T. Liu, S. Oscarson, T. Norberg, C.F. Brewer, Thermodynamic binding studies of cell surface carbohydrate epitopes to galectins-1, -3 , and -7 : evidence for differential binding specificities, Can. J. Chem. 80 (2002) 1096-1104.

[19] J. Hirabayashi, T. Hashidate, Y. Arata, N. Nishi, T. Nakamura, M. Hirashima, T. Urashima, T. Oka, M. Futai, W.E.G. Müller, F. Yagi, K.-i. Kasai, Oligosaccharide specificity of galectins: a search by frontal affinity chromatography, Biochim. Biophys. Acta 1572 (2002) 232-254

[20] T.K. Dam, H.-J. Gabius, S. André, H. Kaltner, M. Lensch, C.F. Brewer, Galectins bind to the multivalent glycoprotein asialofetuin with enhanced affinities and a gradient of decreasing binding constants, Biochemistry 44 (2005) $12564-12571$

[21] S. André, S. Kojima, G. Gundel, R. Russwurm, X. Schratt, C. Unverzagt, H.-J. Gabius, Branching mode in complex-type triantennary N-glycans as regulatory element of their ligand properties, Biochim. Biophys. Acta 1760 (2006) 768-782.

[22] E.M. Rapoport, S. André, O.V. Kurmyshkina, T.V. Pochechueva, V.V. Severov, G.V. Pazynina, H.-J. Gabius, N.V. Bovin, Galectin-loaded cells as a platform for the profiling of lectin specificity by fluorescent neoglycoconjugates: a case study on galectins-1 and -3 and the impact of assay setting, Glycobiology 18 (2008) 315-324.

[23] S.R. Stowell, C.M. Arthur, P. Mehta, K.A. Slanina, O. Blixt, H. Leffler, D.F. Smith, R.D. Cummings, Galectins-1, -2 , and -3 exhibit differential recognition of sialylated glycans and blood group antigens, J. Biol. Chem. 283 (2008) 10109-10123.

[24] H. Tateno, A. Mori, N. Uchiyama, R. Yabe, J. Iwaki, T. Shikanai, T. Angata, H. Narimatsu, J. Hirabayashi, Glycoconjugate microarray based on an evanescentfield fluorescence-assisted detection principle for investigation of glycan-binding proteins, Glycobiology 18 (2008) 789-798.

[25] P. Szabo, T.K. Dam, K. Smetana Jr., B. Dvořánková, D. Kübler, C.F. Brewer, H.-J. Gabius, Phosphorylated human lectin galectin-3: analysis of ligand binding by histochemical monitoring of normal/malignant squamous epithelia and by isothermal titration calorimetry, Anat. Histol. Embryol. 38 (2009) 68-75.

[26] D.W. Ohannesian, D. Lotan, P. Thomas, J.M. Jessup, M. Fukuda, H.-J. Gabius, R. Lotan, Carcinoembryonic antigen and other glycoconjugates act as ligands for galectin-3 in human colon carcinoma cells, Cancer Res. 55 (1995) 2191-2199.

[27] R.S. Bresalier, J.C. Byrd, L. Wang, A. Raz, Colon cancer mucin: a new ligand for the $\beta$-galactoside-binding protein galectin-3, Cancer Res. 56 (1996) 4354-4357.

[28] S. Ramasamy, S. Duraisamy, S. Barbashov, T. Kawano, S. Kharbanda, D. Kufe, The MUC1 and galectin-3 oncoproteins function in a microRNA-dependent regulatory loop, Mol. Cell 27 (2007) 992-1004.

[29] N. Díez-Revuelta, S. Velasco, S. André, H. Kaltner, D. Kübler, H.-J. Gabius, J. AbadRodriguez, Phosphorylation of adhesion- and growth-regulatory human galectin3 leads to the induction of axonal branching by local membrane L1 and ERM redistribution, J. Cell Sci. 123 (2010) 671-681.

[30] S.M. Massa, D.N.W. Cooper, H. Leffler, S.H. Barondes, L-29, an endogenous lectin, binds to glycoconjugate ligands with positive cooperativity, Biochemistry 32 (1993) 260-267

[31] S. André, B. Liu, H.-J. Gabius, R. Roy, First demonstration of differential inhibition of lectin binding by synthetic tri- and tetravalent glycoclusters from crosscoupling of rigidified 2-propynyl lactoside, Org. Biomol. Chem. 1 (2003) 3909-3916.

[32] N. Ahmad, H.-J. Gabius, S. André, H. Kaltner, S. Sabesan, R. Roy, B. Liu, F. Macaluso, C.F. Brewer, Galectin-3 precipitates as a pentamer with synthetic multivalent carbohydrates and forms heterogeneous cross-linked complexes, J. Biol. Chem. 279 (2004) 10841-10847.

[33] S. André, D. Specker, N.V. Bovin, M. Lensch, H. Kaltner, H.-J. Gabius, V. Wittmann, Carbamate-linked lactose: design of clusters and evidence for selectivity to block binding of human lectins to (neo)glycoproteins with increasing degree of branching and to tumor cells, Bioconjug. Chem. 20 (2009) 1716-1728.

[34] H.-J. Gabius, Cell surface glycans: the why and how of their functionality as biochemical signals in lectin-mediated information transfer, Crit. Rev. Immunol. 26 (2006) 43-79.

[35] C. Zuber, J. Roth, N-Glycosylation, in: H.-J. Gabius (Ed.), The Sugar Code. Fundamentals of Glycosciences, Wiley-VCH, Weinheim, Germany, 2009, pp. 87-110.

[36] G. Patsos, A. Corfield, O-Glycosylation: structural diversity and functions, in: H.-J. Gabius (Ed.), The Sugar Code. Fundamentals of Glycosciences, Wiley-VCH, Weinheim, Germany, 2009, pp. 111-137.

[37] C. Dominguez, R. Boelens, A.M.J.J. Bonvin, HADDOCK: a protein-protein docking approach based on biochemical or biophysical information, J. Am. Chem. Soc. 125 (2003) 1731-1737.

[38] S.J. de Vries, A.D.J. van Dijk, M. Krzeminski, M. van Dijk, A. Thureau, V. Hsu, T. Wassenaar, A.M.J.J. Bonvin, HADDOCK versus HADDOCK: new features and performance of HADDOCK2.0 on the CAPRI targets, Proteins 69 (2007) 726-733.
[39] A.M. Wu, T. Singh, J.-H. Liu, M. Krzeminski, R. Russwurm, H.-C. Siebert, A.M.J.J Bonvin, S. André, H.-J. Gabius, Activity-structure correlations in divergent lectin evolution: fine specificity of chicken galectin CG-14 and computational analysis of flexible ligand docking for CG-14 and the closely related CG-16, Glycobiology 17 (2007) 165-184.

[40] N. Nagy, H. Legendre, O. Engels, S. André, H. Kaltner, K. Wasano, Y. Zick, J.C. Pector, C. Decaestecker, H.-J. Gabius, I. Salmon, R. Kiss, Refined prognostic evaluation in colon carcinoma using immunohistochemical galectin fingerprinting, Cancer 97 (2003) 1849-1858

[41] S. Langbein, J. Brade, J.K. Badawi, M. Hatzinger, H. Kaltner, M. Lensch, K. Specht, S André, U. Brinck, P. Alken, H.-J. Gabius, Gene-expression signature of adhesion/ growth-regulatory tissue lectins (galectins) in transitional cell cancer and its prognostic relevance, Histopathology 51 (2007) 681-690.

[42] Z. Čada, K. Smetana Jr., L. Lacina, Z. Plzáková, J. Štork, H. Kaltner, R. Russwurm, M. Lensch, S. André, H.-J. Gabius, Immunohistochemical fingerprinting of the network of seven adhesion/growth-regulatory lectins in human skin and detection of distinct tumor-associated alterations, Folia Biol. (Praha) 55 (2009) 145-152.

[43] T. Purkrábková, K. Smetana Jr., B. Dvořánková, Z. Holíková, C. Böck, M. Lensch, S André, R. Pytlík, F.-T. Liu, J. Klíma, K. Smetana, J. Motlík, H.-J. Gabius, New aspects of galectin functionality in nuclei of cultured bone marrow stromal and epidermal cells: biotinylated galectins as tool to detect specific binding sites, Biol. Cell 95 (2003) 535-545.

[44] D. Kübler, C.-W. Hung, T.K. Dam, J. Kopitz, S. André, H. Kaltner, M. Lohr, J.C. Manning, L. He, H. Wang, A. Middelberg, C.F. Brewer, J. Reed, W.-D. Lehmann, H.-J Gabius, Phosphorylated human galectin-3: facile large-scale preparation of active lectin and detection of structural changes by CD spectroscopy, Biochim. Biophys. Acta 1780 (2008) 716-722.

[45] S. André, Z. Pei, H.-C. Siebert, O. Ramström, H.-J. Gabius, Glycosyldisulfides from dynamic combinatorial libraries as O-glycoside mimetics for plant and endogenous lectins: their reactivities in solid-phase and cell assays and conformationa analysis by molecular dynamics simulations, Bioorg. Med. Chem. 14 (2006) 6314-6326.

[46] S. André, F. Sansone, H. Kaltner, A. Casnati, J. Kopitz, H.-J. Gabius, R. Ungaro, Calix [n]arene-based glycoclusters: bioactivity of thiourea-linked galactose/lactose moieties as inhibitors of binding of medically relevant lectins to a glycoprotein and cell-surface glycoconjugates and selectivity among human adhesion/growthregulatory galectins, ChemBioChem 9 (2008) 1649-1661.

[47] A.M. Wu, J.H. Wu, M.-S. Tsai, H. Kaltner, H.-J. Gabius, Carbohydrate specificity of a galectin from chicken liver (CG-16), Biochem. J. 358 (2001) 529-538.

[48] A.M. Wu, J.H. Wu, M.-S. Tsai, J.-H. Liu, S. André, K. Wasano, H. Kaltner, H.-J. Gabius, Fine specificity of domain-I of recombinant tandem-repeat-type galectin- 4 from rat gastrointestinal tract (G4-N), Biochem. J. 367 (2002) 653-664.

[49] J. Montreuil, G. Spik, J. Mazurier, Transferrin superfamily, in: J. Montreuil, J.F.G. Vliegenthart, H. Schachter (Eds.), Glycoproteins II, Elsevier Science B.V. Amsterdam, 1997, pp. 203-242.

[50] H. Yoshima, H. Furthmayr, A. Kobata, Structures of the asparagine-linked sugar chains of glycophorin A, J. Biol. Chem. 255 (1980) 9713-9718.

[51] D.H. Joziasse, W.E.C.M. Schiphorst, D.H. van den Eijnden, J.A. van Kuik, H. van Halbeek, J.F.G. Vliegenthart, Branch specificity of bovine colostrum CMP-sialic acid: Gal $\beta 1-4 G l c N A c-R \quad \alpha 2 \rightarrow 6$-sialyltransferase. Sialylation of bi-, tri-, and tetraantennary oligosaccharides and glycopeptides of the $\mathrm{N}$-acetyllactosamine type, J. Biol. Chem. 262 (1987) 2025-2033.

[52] A.M. Wu, T. Singh, J.H. Wu, M. Lensch, S. André, H.-J. Gabius, Interaction profile of galectin-5 with free saccharides and mammalian glycoproteins: probing its fine specificity and the effect of naturally clustered ligand presentation, Glycobiology 16 (2006) 524-537.

[53] H.-C. Siebert, S. André, S.-Y. Lu, M. Frank, H. Kaltner, J.A. van Kuik, E.Y. Korchagina, N.V. Bovin, E. Tajkhorshid, R. Kaptein, J.F.G. Vliegenthart, C.-W. von der Lieth, J Jiménez-Barbero, J. Kopitz, H.-J. Gabius, Unique conformer selection of human growth regulatory lectin galectin- 1 for ganglioside $\mathrm{GM}_{1}$ versus bacterial toxins, Biochemistry 42 (2003) 14762-14773.

[54] F. Strino, J.-H. Lii, H.-J. Gabius, P.-G. Nyholm, Conformational analysis of thioglycoside derivatives of histo-blood group $\mathrm{ABH}$ antigens using an $a b$ initioderived reparameterization of MM4: implications for design of non-hydrolysable mimetics, J. Comput. Aided Mol. Des. 23 (2009) 845-852.

55] P. Sörme, P. Arnoux, B. Kahl-Knutsson, H. Leffler, J.M. Rini, U.J. Nilsson, Structura and thermodynamic studies on cation- $\pi$ interactions in lectin-ligand complexes: high-affinity galectin-3 inhibitors through fine-tuning of an arginine-arene interaction, J. Am. Chem. Soc. 127 (2005) 1737-1743.

[56] D. Solís, A. Romero, H. Kaltner, H.-J. Gabius, T. Díaz-Mauriño, Different architecture of the combining site of the two chicken galectins revealed by chemical mapping studies with synthetic ligand derivatives, J. Biol. Chem. 271 (1996) 12744-12748.

57] M. Lohr, M. Lensch, S. André, H. Kaltner, H.-C. Siebert, K. Smetana Jr., F. Sinowatz H.-J. Gabius, Murine homodimeric adhesion/growth-regulatory galectins-1, -2 and -7: comparative profiling of gene/promoter sequences by database mining, of expression by RT-PCR/immunohistochemistry and of contact sites for carbohydrate ligands by computational chemistry, Folia Biol. (Praha) 53 (2007) 109-128.

[58] H. Kaltner, D. Solís, J. Kopitz, M. Lensch, M. Lohr, J.C. Manning, M. Mürnseer, M. Schnölzer, S. André, J. Sáiz, H.-J. Gabius, Prototype chicken galectins revisited: characterization of a third protein with distinctive hydrodynamic behaviour and expression pattern in organs of adult animals, Biochem. J. 409 (2008) 591-599.

[59] S. André, D. Giguère, T.K. Dam, F. Brewer, H.-J. Gabius, R. Roy, Synthesis and screening of a small glycomimetic library for inhibitory activity on medically relevant galactoside-specific lectins in assays of increasing biorelevance, New J. Chem. 34 (2010) 2229-2240. 
[60] J.H. Wu, T. Singh, A. Herp, A.M. Wu, Carbohydrate recognition factors of the lectin domains present in the Ricinus communis toxic protein (Ricin), Biochimie 88 (2006) 201-217.

[61] A.M. Wu, J.H. Wu, J.-H. Liu, T. Singh, S. André, H. Kaltner, H.-J. Gabius, Effects of polyvalency of glycotopes and natural modifications of human blood group $\mathrm{ABH} /$ Lewis sugars at the Galß1-terminated core saccharides on the binding of domain-I of recombinant tandem-repeat-type galectin-4 from rat gastrointestinal tract (G4-N), Biochimie 86 (2004) 317-326.

[62] M.F. López-Lucendo, D. Solís, S. André, J. Hirabayashi, K.-i. Kasai, H. Kaltner, H.-J. Gabius, A. Romero, Growth-regulatory human galectin-1: crystallographic characterisation of the structural changes induced by single-site mutations and their impact on the thermodynamics of ligand binding, J. Mol. Biol. 343 (2004) 957-970.

[63] M.F. López-Lucendo, D. Solís, J.L. Sáiz, H. Kaltner, R. Russwurm, S. André, H.-J. Gabius, A. Romero, Homodimeric chicken galectin CG-1B (C-14): crystal structure and detection of unique redox-dependent shape changes involving inter- and intrasubunit disulfide bridges by gel filtration, ultracentrifugation, site-directed mutagenesis and peptide mass fingerprinting, J. Mol. Biol. 386 (2009) 366-378.

[64] S. André, H. Kaltner, M. Lensch, R. Russwurm, H.-C. Siebert, C. Fallsehr, E. Tajkhorshid, A.J.R. Heck, M. von Knebel-Döberitz, H.-J. Gabius, J. Kopitz, Determination of structural and functional overlap/divergence of five prototype galectins by analysis of the growth-regulatory interaction with ganglioside $\mathrm{GM}_{1}$ in silico and in vitro on human neuroblastoma cells, Int. J. Cancer 114 (2005) 46-57.

[65] J. Kopitz, M. Bergmann, H.-J. Gabius, How adhesion/growth-regulatory galectins-1 and -3 attain cell specificity: case study defining their target on neuroblastoma cells (SK-N-MC) and marked affinity regulation by affecting microdomain organization of the membrane, IUBMB Life 62 (2010) 624-628.

[66] A.R. Todeschini, S.-i. Hakomori, Functional role of glycosphingolipids and gangliosides in control of cell adhesion, motility, and growth, through glycosynaptic microdomains, Biochim. Biophys. Acta 1780 (2008) 421-433.

[67] C.-W. von der Lieth, H.-C. Siebert, T. Kožár, M. Burchert, M. Frank, M. Gilleron, H Kaltner, G. Kayser, E. Tajkhorshid, N.V. Bovin, J.F.G. Vliegenthart, H.-J. Gabius, Lectin ligands: new insights into their conformations and their dynamic behavior and the discovery of conformer selection by lectins, Acta Anat. 161 (1998) 91-109.

[68] K. Henrick, S. Bawumina, E.A.M. Barboni, B. Mehul, R.C. Hughes, Evidence for subsites in the galectins involved in sugar binding at the nonreducing end of the central galactose of oligosaccharide ligands: sequence analysis, homology modeling and mutagenesis studies of hamster galectin-3, Glycobiology 8 (1998) 45-57.

[69] T.K. Mandal, C. Mukhopadhyay, Binding free energy calculations of galectin-3ligand interactions, Protein Eng. 15 (2002) 979-986.

[70] C. Diehl, S. Genheden, K. Modig, U. Ryde, M. Akke, Conformational entropy changes upon lactose binding to the carbohydrate recognition domain of galectin3. J. Biol. NMR 45 (2009) 157-169.

[71] S. André, C. Elizabeth, C.E.P. Maljaars, K.M. Halkes, H.-J. Gabius, J.P. Kamerling, Discovery of galectin ligands in fully randomized combinatorial one-bead-onecompound (glyco)peptide libraries, Bioorg. Med. Chem. Lett. 17 (2007) 793-798.
[72] L. Frol'ová, K. Smetana Jr., D. Borovská, A. Kitanovičová, K. Klimešová, I. Janatková, K. Malíčková, M. Lukáš, P. Drastich, Z. Beneš, L. Tučková, J.C. Manning, S. André, H.-J. Gabius, H. Tlaskalová-Hogenová, Detection of galectin-3 in patients with inflammatory bowel diseases: new serum marker of active forms of IBD? Inflamm. Res. 58 (2009) 503-512.

[73] R. Schwartz-Albiez, Inflammation and glycosciences, in: H.-J. Gabius (Ed.), The Sugar Code. Fundamentals of Glycosciences, Wiley-VCH, Weinheim, Germany, 2009, pp. 447-467.

[74] M.M. Kadrofske, K.P. Openo, J.L. Wang, The human LGALS3 (galectin-3) gene: determination of the gene structure and functional characterization of the promoter, Arch. Biochem. Biophys. 349 (1998) 7-20.

[75] M. Stock, H. Schäfer, S. Stricker, G. Gross, S. Mundlos, F. Otto, Expression of galectin-3 in skeletal tissues is controlled by Runx2, J. Biol. Chem. 278 (2003) $17360-17367$.

[76] V. Vladimirova, A. Waha, K. Lückerath, P. Pesheva, R. Probstmeier, Runx2 is expressed in human glioma cells and mediates the expression of galectin-3, J. Neurosci. Res. 86 (2008) 2450-2461.

[77] H.-Y. Zhang, L. Jin, G.A. Stilling, K.H. Ruebel, K. Coonse, Y. Tanizaki, A. Raz, R.V. Lloyd, RUNX1 and RUNX2 upregulate galectin-3 expression in human pituitary tumors, Neuroendocrinology 35 (2009) 101-111.

[78] D. Gratzinger, S. Zhao, R. West, R.V. Rouse, H. Vogel, E. Cubedo Gil, R. Levy, I.S. Lossos, Y. Natkunam, The transcription factor LMO2 is a robust marker of vascular endothelium and vascular neoplasms and selected other entities, Am. J. Clin. Pathol. 131 (2009) 264-278.

[79] I.-C. Ho, T.-S. Tai, S.-Y. Pai, GATA3 and the T-cell lineage: essential functions before and after T-helper-2-cell differentiation, Nat. Rev. Immunol. 9 (2009) 125-135.

[80] J.H. Ko, E. Miyoshi, K. Noda, A. Ekuni, R. Kang, Y. Ikeda, N. Taniguchi, Regulation of the GnT-V promoter by transcription factor Ets-1 in various cancer cell lines, J. Biol. Chem. 274 (1999) 22941-22948.

[81] T. Sato, K. Furukawa, Sequential action of Ets-1 and Sp1 in the activation of the human $\beta$-1,4-galactosyltransferase $\mathrm{V}$ gene involved in abnormal glycosylation characteristic of cancer cells, J. Biol. Chem. 282 (2007) 27702-27712.

[82] C. Saravanan, Z. Cao, S.R. Head, N. Panjwani, Analysis of differential expression of glycosyltransferases in healing corneas by glycogene microarrays, Glycobiology 20 (2010) 13-23.

[83] S. André, H. Sanchez-Ruderisch, H. Nakagawa, M. Buchholz, J. Kopitz, P. Forberich, W. Kemmner, C. Böck, K. Deguchi, K.M. Detjen, B. Wiedenmann, M. von Knebel Doeberitz, T.M. Gress, S.-I. Nishimura, S. Rosewicz, H.-J. Gabius, Tumor suppressor p16 $6^{\text {INK4a: }}$ modulator of glycomic profile and galectin-1 expression to increase susceptibility to carbohydrate-dependent induction of anoikis in pancreatic carcinoma cells, FEBS J. 274 (2007) 3233-3256.

[84] H.-J. Gabius, Glycans: bioactive signals decoded by lectins, Biochem. Soc. Trans. 36 (2008) 1491-1496

[85] H. Sanchez-Ruderisch, C. Fischer, K.M. Detjen, M. Welzel, A. Wimmel, J.C. Manning, S. André, H.-J. Gabius, Tumor suppressor p16 ${ }^{\mathrm{INK} 4 \mathrm{a}}$ : downregulation of galectin-3, an endogenous competitor of the pro-anoikis effector galectin-1, in a pancreatic carcinoma model, FEBS J. 277 (2010) 3552-3563. 